\title{
Bankruptcy and Cross-Country Differences in Productivity
}

\author{
Julian Neira ${ }^{1}$ \\ Department of Economics, University of Exeter Business School, 0.43 Streatham Court, \\ Exeter EX4 4PU, United Kingdom.
}

\begin{abstract}
For a sample of OECD countries, I document a systematic positive relationship between i) aggregate productivity, ii) the employment share by large firms and iii) the proportion of large firms in the economy. I propose that differences in bankruptcy procedures can explain this relationship. In a model of financial intermediation and informational frictions, I show that as bankruptcy procedures worsen - measured by the amount a lender can recover from bankrupt borrowers - lenders respond by i) shifting their portfolio of loans to smaller (less productive) firms and ii) lending less. This finding is supported by empirical evidence: across countries, efficient bankruptcy procedures are associated with a higher proportion of new bank loans allocated to large firms. In the model, moving the level of recovery rate from the U.S. level to that of the lowest recovery rate country in the OECD sample reduces TFP by around 30 percent.
\end{abstract}

Keywords: Aggregate Productivity, Bankruptcy, Financial Frictions, Misallocation, Small Firms, Employment Shares

\footnotetext{
Email address: julianneira@gmail.com (Julian Neira)

URL: https://sites.google.com/site/julianneira/ (Julian Neira)

${ }^{1}$ A previous version of this paper was circulated under the title Recovery Rate, Misallocation of Talent and Cross-Country Productivity Differences. I am particularly grateful to Juan Sanchez and Javier Birchenall for helpful early discussions of this paper. I also thank Peter Rupert, Finn Kydland, Marek Kapička, Rish Singhania, Francesco Casellli, four anonymous referees and participants at the RES, SED, SAET, EEA/ESEM, Midwest Macro, and FDES conferences and seminar participants at the Colombian Central Bank, CERGE-EI, Houston, IADB, Javeriana, KU Lueven, UCSB and other venues for helpful comments and discussion. All errors are my own. Conflicts of interest: none.
} 
JEL: E44, E23, E02, D24, O47

\section{Introduction}

A well-established fact in economics is that income differences across countries are accounted for largely by differences in aggregate productivity. ${ }^{2}$ However, improving the aggregate productivity of poorer countries requires identifying specific policies that are responsible for these differences in productivity. In this paper, I propose that one particular policy, the efficiency of bankruptcy procedures, is an important source of differences in aggregate productivity. ${ }^{3}$

The starting point of this paper is to note that aggregate productivity is a weighted average of firm-level productivities. Therefore, aggregate productivity can be decomposed into levels and weights. For example, aggregate labor productivity can be decomposed into each firm's labor productivity and employment share. Using a harmonized dataset constructed from national statistical agencies' data for a sample of OECD countries, I first document that firm size (number of employees) and firm-level labor productivity are positively correlated in each country - that is, larger firms tend to be more productive than smaller firms. I then document that countries with higher aggregate labor productivity tend to have i) a greater share of their workforce employed in large firms and ii) a greater proportion of large firms in the economy.

Differences in employment shares are an important component of the differences in aggregate labor productivity across countries. An Olley-Pakes decomposition suggests that up to 36 percent of the difference in aggregate labor productivity among OECD countries can be attributed to differences in employment shares. In order to place this magnitude into perspective, the decomposition exercise suggests that Spain and Italy would be as productive as Germany if they had Germany's employment shares.

I develop a model of bankruptcy and show that the efficiency of bankruptcy procedures, measured as the percentage of a loan a lender can recover from

\footnotetext{
${ }^{2}$ See Hsieh and Klenow (2010) and references therein.

${ }^{3}$ One reason that the link between bankruptcy procedures and aggregate productivity may have been relatively unexplored is the lack, until recently, of comparable cross-country data on bankruptcy.
} 
a bankrupt borrower, affects the weights of the firm-size distribution. Thus, differences in bankruptcy efficiency generate differences in the employment share of large firms, the proportion of large firms, and aggregate productivity consistent with the data. The insight that arises from the model is that countries with less efficient bankruptcy procedures tend to have lower aggregate productivity because their bankruptcy procedures induce lenders to allocate funds to smaller (less productive) firms in order to separate productive from less-productive projects. There is empirical support for this mechanism: data from the European Central Bank shows that, across countries, efficient bankruptcy procedures are associated with a higher proportion of new bank loans allocated to large firms.

Why focus on bankruptcy procedures instead of other potential sources of aggregate productivity differences? First, there is direct evidence that bankruptcy reform leads to changes in the size distribution of firms (Ponticelli and Alencar (2016), discussed in Section 1.1). Second, World Bank measures of bankruptcy efficiency are highly correlated with employment shares across countries (see Section 2.3). Third, evidence suggests that access to finance is an important determinant of firm size. ${ }^{4}$ It has also been documented that banks adjust their lending practices in response to bankruptcy procedures (Davydenko and Franks, 2008) and that bankruptcy reforms affect credit markets. ${ }^{5}$ These reasons point towards bankruptcy as a promising candidate for explaining variation in employment shares through firm access to finance.

Description of the Model. I consider a static Lucas (1978) span of control environment, augmented along the lines of Erosa and Hidalgo-Cabrillana (2008) to introduce financial intermediation. The model features a competitive lender and a continuum of households. If households fail to secure funding to start a firm (become entrepreneurs), they rent their labor for a wage (become workers). Households are endowed with either high or low entrepreneurial productivity but have identical abilities as workers. The lender wants to allocate resources to high-productivity entrepreneurs, but

\footnotetext{
${ }^{4}$ For example, Evans and Jovanovic (1989) and Cabral and Mata (2003) argue that financing constraints, particularly those of startups, are important in shaping the firmsize distribution.

${ }^{5}$ See Araujo et al. (2012) for evidence from Brazil, Gamboa-Cavazos and Schneider (2007) for Mexico, Rodano et al. (2015) for Italy, and Lambert-Mogiliansky et al. (2007) for Russia.
} 
is constrained by two frictions. First, entrepreneurial productivity is private information of the entrepreneurs. However, productivity can be inferred by lenders after production has taken place. Hence, the lender could achieve first-best allocations if it could impose unlimited penalties on entrepreneurs who misrepresent their productivity-type. The second friction limits the penalty the lender can impose for false productivity reports. An exogenous limit on the penalty for false reports can be mapped to the level of bankruptcy efficiency in equilibrium, as this limit dictates the percentage of the loan that the lender can recover from borrowers who misrepresent their productivity and do not have enough resources to pay back the full amount of the loan.

In equilibrium, as the level of bankruptcy efficiency decreases, two forces decrease aggregate productivity. First, the average firm productivity decreases. This effect is due to the tightening of the incentive compatibility constraint of low-productivity households; as low-productivity households face a weaker punishment for misrepresenting their productivity, the lender deters them from lying by increasing their probability of obtaining a loan relative to high-productivity households. In the aggregate, then, there is a higher proportion of low-productivity firms than before. Second, the number of high-productivity firms decreases. This effect comes from the lender's feasibility constraint, as funding for low-productivity firms reduces the available funding remaining for high-productivity firms.

An important characteristic of the environment is that the optimal contract does not distort the firm-size margin. Thus, conditional on obtaining funding, firms secure enough capital and labor to operate at their optimal size. This has two implications. First, there is no capital misallocation among existing firms as there is no dispersion of marginal products. Hence, bankruptcy affects aggregate productivity solely through firm selection. ${ }^{6}$ Second, for a given recovery rate, there is a one-to-one mapping between firm productivity and firm size. By construction, firm-level Total Factor Productivity (TFP) levels are exogenous and therefore invariant with bankruptcy efficiency. Aggregate TFP then varies with bankruptcy efficiency solely through the weights of the firm-size distribution.

The paper then proceeds to endogenize wages. Endogenous wages amplify the differences in TFP. Lower bankruptcy efficiency decreases aggregate pro-

\footnotetext{
${ }^{6}$ Put differently, there is capital misallocation on the extensive margin, but not on the intensive margin.
} 
ductivity, which lowers total output, which in turn depresses wages. Lower wages decrease the value of the outside option for entrepreneurs, reinforcing private information frictions by increasing the incentives of low-productivity households to misreport their type. Lenders respond by allocating even more funding to low-productivity firms at the expense of high-productivity firms, and worse selection decreases aggregate productivity further.

The model is calibrated to the establishment-size distribution and bankruptcy efficiency of the United States. The quantitative experiment asks how much the United States' TFP would change if its bankruptcy processes were as efficient as those of other countries. Given OECD bankruptcy efficiency rates, the model generates a drop in aggregate TFP of up to 30 percent and a drop in aggregate labor productivity of up to 45 percent. This is close to the aggregate labor productivity differences between the United States and Greece, the country in the sample with the lowest recovery rate and lowest aggregate productivity measure.

Intuitively, large TFP effects that result from imperfect selection are consistent with Hopenhayn's (2014) rank reversal. Hopenhayn (2014) shows analytically that the distortions that have the greatest potential to generate large TFP effects are those that flip the size-ranking of firms from an undistorted economy to the distorted economy. Imperfect selection is an extreme form of rank reversal: Some of the large firms in an undistorted economy become zero-size firms in the distorted economy.

\subsection{Relationship to the existing literature}

Spurred by Restuccia and Rogerson's (2008) and Hsieh and Klenow's (2009) seminal work, the literature has identified that a potentially important source of differences in aggregate productivity are distortions that cause inputs to be inefficiently allocated across heterogeneous production units. This paper contributes to a literature that seeks to tie such distortions to directly measurable policies. ${ }^{7}$ A related literature focuses on financial frictions as a source of capital misallocation across existing firms. ${ }^{8}$ Particularly

\footnotetext{
${ }^{7}$ Examples include firing costs (Hopenhayn and Rogerson, 1993), unemployment insurance and employment protection (Lagos, 2006), size-dependent policies (Guner, Ventura and Yi, 2008), trade barriers (Eslava et al., 2013; Bond et al., 2013), and entry regulations (Barseghyan and DiCecio, 2011; Moscoso-Boedo and Mukoyama, 2012).

${ }^{8}$ Recent examples are Amaral and Quintin (2010), Buera, Kaboski and Shin (2011), Caselli and Gennaioli (2013), Steinberg (2013), Greenwood, Sanchez and Wang (2013),
} 
related to this paper are some working papers that explicitly incorporate bankruptcy as a determinant of financial frictions (Rodriguez-Delgado, 2010; Corbae and D'Erasmo, 2014; Senkal, 2014; Tamayo, 2015). In contrast to these financial frictions papers, this paper abstracts from misallocation of capital among existing firms. ${ }^{9}$ Instead of focusing on dispersion of marginal products, it highlights selection of firms as the mechanism by which financial frictions affect aggregate productivity.

To deliver the model's tractability, I build on theoretical work by Erosa and Hidalgo-Cabrillana (2008). As in their framework, the model of financial intermediation has analytical solutions, and contracting over weights of the firm-size distribution improves welfare. An important difference between the modelling framework of this paper and Erosa and Hidalgo-Cabrillana (2008)'s is that firms in their economy have constant returns to scale technologies, which paired with a fixed cost implies increasing returns. Hence, a determinate firm size is obtained by imposing an exogenous maximum firm size. This modelling assumption is innocuous in their framework because they are pursuing facts unrelated to firm size. I dispense with the assumption of constant returns and replace it with decreasing returns to scale technologies that deliver a non-degenerate firm-size distribution. This difference is not minor: with decreasing returns to scale, the solution to the optimal contract is such that, conditional on funding, firm size is optimal, which is why there is no dispersion in marginal products. As a result, the model delivers a closed-form solution for aggregate TFP.

Direct evidence for the effects of bankruptcy procedures on firm-size distributions comes from Ponticelli and Alencar (2016), who study the impact of a reform in Brazilian bankruptcy law that improved Brazil's bankruptcy efficiency. The identification strategy relies on differences in the application

\footnotetext{
Moll (2014), and Cole, Greenwood and Sanchez (2016).

${ }^{9}$ The theory of misallocation of capital among existing firms faces at least two challenges. First, recent literature has highlighted that dispersion of marginal products in the data need not be evidence of distortions (Caunedo, 2015; Bartelsman, Haltiwanger and Scarpetta, 2013). Second, the quantitative importance of this channel is undermined by firms' ability to save their way out of borrowing constraints (Banerjee and Moll, 2010; Midrigan and $\mathrm{Xu}, 2014)$, their ability of firms to pledge earnings as well as assets ( $\mathrm{Li}$, 2015), and large measured dispersions' not implying large distortions (Gilchrist, Sim and Zakrajsek, 2013). Using data from South Korea, Colombia, and China, Midrigan and Xu (2014) find that the bulk of TFP losses from financial frictions are due to selection rather than to misallocation of capital among existing firms.
} 
of the reform across judicial districts due to differences in the congestion of local courts. Crucially, Brazilian laws do not allow creditors or firms to choose the district in which to file a bankruptcy case. Ponticelli and Alencar (2016) find that bankruptcy reform led to an increase in secured loans to manufacturing firms, as well as an increase in investment and average firm size.

One contribution of the paper is to document the strong positive correlation between aggregate productivity, the employment share of large firms, and the proportion of large firms in the economy. Related work that documents differences in the size distribution of firms across countries has focused on the manufacturing sector. For example, Hsieh and Klenow (2014) and Bento and Restuccia (forthcoming) document a positive relationship between average firm size and aggregate productivity. Bartelsman, Haltiwanger and Scarpetta (2013) finds a large dispersion of labor productivity in a set of countries. I find that these observations hold for broad as well as narrowly defined sectors of the economy, which suggests a role for firm-level, rather than sector-level, explanations. An exception to the focus on manufacturing is contemporaneous work by Poschke (2015), who uses Global Entrepreneurship Monitor (GEM) data (for small firms) and Amadeus data (for larger firms) to document that, in a sample of roughly 30 countries, large firms are more prevalent and account for a larger fraction of employment in richer countries. A limitation of GEM, as compared to the OECD/Eurostat SDBS used in this paper, is that it does not include information on value added, and hence, labor productivity.

The current paper proceeds as follows. Section 2 discusses the motivating facts. Section 3 presents the model. Section 4 discusses how the model is taken to the data. Section 5 discusses the calibration, Section 6 presents the quantitative findings, and Section 7 concludes.

\section{Motivating Facts}

\subsection{OECD Firm Data}

The firm-level data in this paper comes from the OECD/Eurostat Structural and Demographic Business Statistics database. The data is broken out by industry and by firm size class (number of employees). The OECD makes a particular effort to harmonize industry, firm size class and variable definitions across countries. An advantage of this database is that data are compiled directly by national statistical agencies from business registers and 
enterprise surveys, so they are representative of the universe of registered firms. ${ }^{10}$ A drawback of this database is that it is not possible to calculate TFP at the firm level because of missing capital and investment data. Hence, this empirical section focuses on labor productivity, interesting in itself, but also used as a proxy for TFP. ${ }^{11}$

The firm-level data of the twelve countries included in the analysis covers the period from 2004 to 2009. ${ }^{12}$ The results presented report findings for the widest available private sector grouping: the Total Industry, Market Services and Construction sector (ISIC Rev.3 10-74). This sector accounts for 70-80 percent of these economies' value added. ${ }^{13}$

Table 1 reports two statistics that describe the relationship between firm size and firm-level labor productivity. ${ }^{14}$ For virtually all countries in the sample, the correlation between firm-size class and firm-labor productivity is high and positive. A notable exception is Denmark, where small firms are, on average, more productive than the largest firms. However, excluding the smallest firms for Denmark yields a correlation of 0.97. Table 1 also reports

\footnotetext{
${ }^{10}$ See Kalemli-Ozcan et al. (2015) for a discussion of sampling issues with Amadeus (ORBIS), the alternative commercial dataset.

${ }^{11}$ Foster, Haltiwanger and Syverson (2008) find a correlation of about 0.6 for TFP and labor productivity for firms in the United States.

${ }^{12}$ The database covers as many as thirty-three countries. No data is available for the year 2008. Countries were excluded from the sample if they were missing data during the 2004-2009 time period, other than for 2008. The sample also excludes former communist countries, countries with populations less than a million during the 2004-2009 time period, and countries in which the oil-rent-to-GDP ratio exceeded 10 percent during 2004-2009. The reason for this exclusion criteria is that the firm composition in these countries may be distorted. The time period is chosen to match the earliest bankruptcy data available and to exclude the disruption of the Great Recession. The underlying data are enterprise(or firm-) level data as opposed to establishment-level data.

${ }^{13}$ According to EU KLEMS data, this sector's share of value added ranges from 71.7 percent in Denmark to 78 percent in Italy for the 2004-2009 period. The excluded sectors are agriculture (ISIC Rev.3 01-05) and public services (ISIC Rev.3 75-99).

${ }^{14}$ Labor productivity at the firm level is measured as value added per employee (engaged). Employee (engaged) counts self-employed enterprises as one employee. While this measure is the relevant one for this analysis as the emphasis is on employment shares, one can find measures of labor productivity that control for hours and quality as well by using value added per unit of payroll instead. The idea is that payroll incorporates hours worked, and to the extent that wages reflect worker quality, it also controls for labor quality. Bartelsman, Haltiwanger and Scarpetta (2013, footnote 5) finds that measures of firm-level labor productivity in the U.S. are robust to using payroll instead of employees.
} 
the labor productivity ratio between the largest and smallest size class. The dispersion in productivity is large: an employee in Portugal who works for a firm with 250 or more employees produces almost three times as much value added as an employee in Portugal who works for a firm with fewer than ten employees. After Denmark, the country with the smallest ratio is the UK, where workers are 20 percent more productive in the largest firms than they are in the smallest firms. ${ }^{15}$

Table 1: Firm size and firm productivity (2004-2009)

\begin{tabular}{rcc}
\hline & $\begin{array}{c}\text { Correlation between firm size class and } \\
\text { firm labor productivity }\end{array}$ & $\begin{array}{c}\text { Labor productivity ratio between } \\
\text { largest and smallest size class }\end{array}$ \\
\hline Austria & 0.97 & 1.56 \\
Belgium & 0.92 & 1.73 \\
Denmark & -0.07 & 0.92 \\
Finland & 0.96 & 1.32 \\
Germany & 0.91 & 1.35 \\
Greece & 0.97 & 2.85 \\
Italy & 0.99 & 2.33 \\
Netherlands & 0.83 & 1.57 \\
Portugal & 0.99 & 2.92 \\
Spain & 0.99 & 1.99 \\
Sweden & 0.94 & 1.39 \\
United Kingdom & 0.85 & 1.24 \\
\hline
\end{tabular}

Notes: Firm labor productivity is Value Added (at factor costs) divided by Total Employment (number engaged). Firm-size classes are 1) 1-9 employees, 2) 10-19 employees, 3) 20-49 employees, 4) 50-249 employees, and 5) 250 or more employees. Data refers to the Total Industry, Market Services, and Construction sector (ISIC Rev.3 10-74). The correlation is calculated each year and then averaged for the 2004-2009 period. Denmark's low correlation is related to the outstanding productivity of its firms in firm-size class 1. When these are excluded, Denmark's correlation is 0.97 and its labor productivity ratio is 1.19 .

Source: SDBS Structural Business Statistics.

Figure 1 shows aggregate labor productivity and the employment share of firms with 250 or more employees. The strong positive correlation in this

\footnotetext{
${ }^{15}$ The positive correlation between firm size and firm-level productivity has been individually identified for various countries (e.g. Spain (Castany, Lpez-Bazo and Moreno, 2005), the U.S. (Foster, Haltiwanger and Syverson, 2008, footnote 16), and Canada (Leung, Meh and Terajima, 2008)). Hsieh and Olken (2014) document a positive correlation between firm size and firm-level labor productivity in India, Indonesia, and Mexico.
} 
figure suggests that productive economies allocate a larger share of their workforce to large firms, which also tend to be the most productive firms. There is also a visible divide between Greece, Portugal, Italy and Spain to which I refer to as South Europe - on one hand and the remaining countries of Austria, Belgium, Denmark, Finland, Germany, Sweden, and United Kingdom - to which I refer as North Europe - on the other. South Europe economies allocate less than 25 percent of their workforces to large firms whereas North Europe economies allocate more than 30 percent of their workforces to large firms.

Figure 1: Employment Share of Large Firms and Labor Productivity (2004-2009)

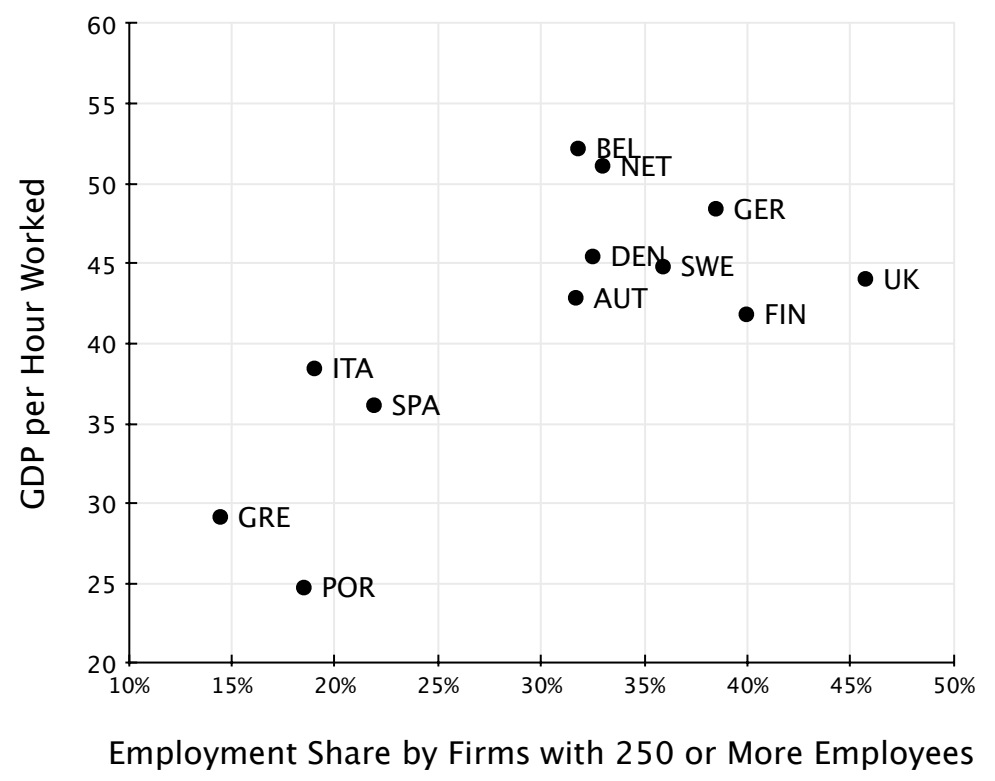

Notes: GDP per hour worked is in real 2005 USD. Employment data is total employees (engaged) for the Total Industry, Market Services, and Construction sector (ISIC Rev.3 10-74). Both statistics are averaged for the 2004-2009 period. The correlation is 0.72. Source: OECD Annual National Accounts and SDBS Structural Business Statistics.

Figure 2 shows aggregate labor productivity and the proportion of large firms in the economy. Productive economies allocate a larger share of their workforces to large firms and large firms make up a larger proportion of firms in these economies. Therefore, it is not the case that a few large firms are responsible for most of the hiring in productive countries; instead, large firms 
are more numerous. Furthermore, Table A-1 in Appendix A shows that these correlations also hold within more narrowly defined industries.

Figure 2: Proportion of Large Firms and Labor Productivity (2004-2009)

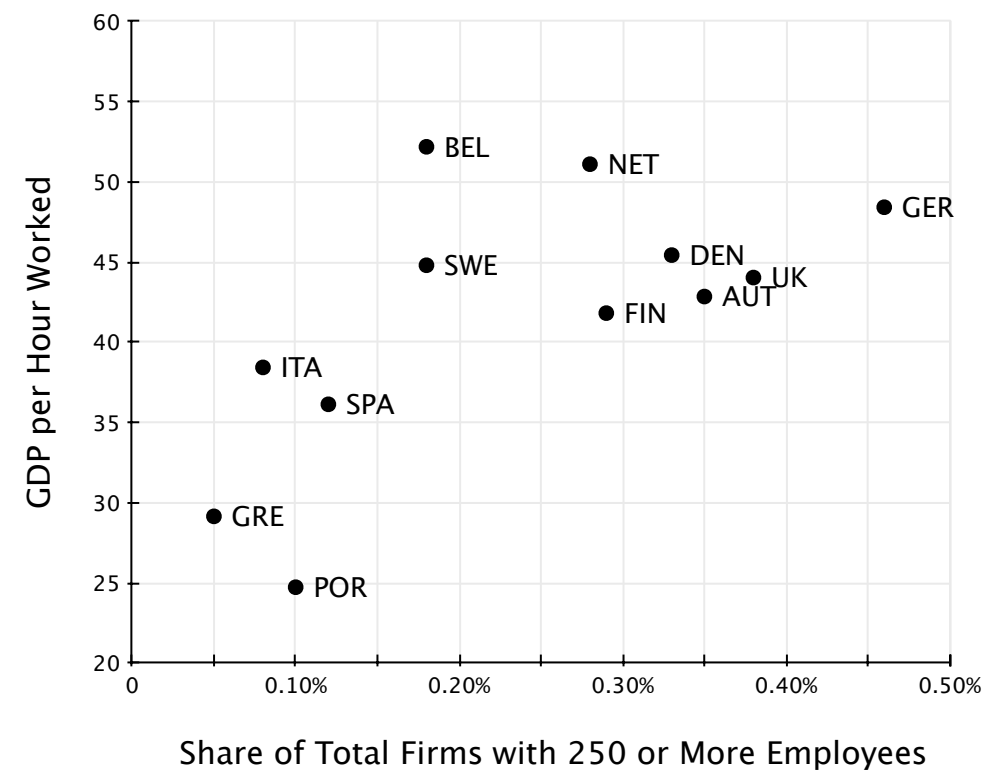

Notes: GDP per hour worked is in real 2005 USD. Enterprise data refers to the Total Industry, Market Services, and Construction sector (ISIC Rev.3 10-74). Both statistics are averaged for the 2004-2009 period. The correlation is 0.64.

Source: OECD Annual National Accounts and SDBS Structural Business Statistics.

Together, these facts suggest that the distribution of labor across firms is an important source of cross-country productivity differences. One can make this statement more precise by decomposing the sources of aggregate productivity into the contribution of average firm productivity and the contribution of labor allocations (employment shares) across firms. The next section presents the results of this the decomposition exercise.

\subsection{How important are employment shares in explaining aggregate produc- tivity differences?}

The Olley and Pakes (1996) measure of aggregate productivity, defined as the weighted average of firm-level productivity $\sum_{i} \theta_{i t} \omega_{i t}$, is decomposed as 


$$
\Theta_{t} \equiv \sum_{i} \theta_{i t} \omega_{i t}=\bar{\theta}_{t}+\sum_{i}\left(\theta_{i t}-\bar{\theta}_{t}\right)\left(\omega_{i t}-\bar{\omega}_{t}\right)
$$

where $\Theta_{t}$ is the weighted productivity index at time $t, \theta_{i}$ is firm-level productivity, $\omega_{i}$ is the share of economic activity, and a "bar" over a variable represents the unweighted industry average of the firm-level measure. The index of productivity is composed of two terms: $\bar{\theta}$, the unweighted productivity term; and the Olley-Pakes (OP) covariance term $\sum_{i}\left(\theta_{i t}-\bar{\theta}_{t}\right)\left(\omega_{i t}-\bar{\omega}_{t}\right)$, which is positive if firms with a higher than average productivity have a higher than average share of activity. In the analysis, $\theta_{i t}$ is the labor productivity at the firm level and $\omega_{i t}$ is the firm's share of employment. Hence, the OP covariance is a measure of misallocation of employment across firms.

The employment shares affect the OP covariance term but not the unweighted productivity term. Therefore, one can get a sense of the impact of employment shares on aggregate productivity by exploring how much of aggregate productivity differences are due to differences in the OP covariance term. The results of this exercise are reported in Table 2.

The first column of Table 2 reports the weighted labor productivity of each country, sorted from highest to lowest. The rankings roughly match the rankings of aggregate labor productivity measured as GDP per hour worked, with Belgium being the most productive nation and Greece being the least productive in the sample. The second column reports the OP covariance term of each country, which is also correlated with GDP-per-hour-worked rankings. The numbers in these two columns confirm that countries with the highest aggregate productivity are precisely those that allocate a larger share of their workforce to the most productive firms. Interestingly, Belgium also has a low OP covariance term, meaning it owes its high productivity to firms being very productive despite its most productive firms not having the highest employment shares.

The last four columns of Table 2 show the results of two counterfactual exercises. The first counterfactual determines how much each country's weighted labor productivity would increase if it had Germany's allocation of labor across firms (as measured by Germany's OP covariance term). The results are most striking for South Europe countries, where large firms have low shares of employment. If they had Germany's allocation of employment, Italy and Spain would be almost as productive as Germany. Greece and Portugal would bridge two-thirds and three-fifths of their productivity gaps with 
Table 2: Olley-Pakes decomposition (2004-2009)

\begin{tabular}{|c|c|c|c|c|c|c|}
\hline & \multirow[b]{3}{*}{$\begin{array}{l}\text { Weighted labor productivity } \\
\qquad(\text { Germany }=100)\end{array}$} & \multirow[b]{3}{*}{$\begin{array}{c}\mathrm{OP} \\
\text { covariance }\end{array}$} & \multicolumn{4}{|c|}{ Counterfactuals } \\
\hline & & & \multicolumn{2}{|c|}{$\begin{array}{l}\text { Germany's } \\
\text { OP covariance }\end{array}$} & \multicolumn{2}{|c|}{$\begin{array}{c}\text { Greece's } \\
\text { OP covariance }\end{array}$} \\
\hline & & & $\begin{array}{l}\text { Weighted labor } \\
\text { productivity }\end{array}$ & $\begin{array}{l}\% \text { change in } \\
\text { productivity }\end{array}$ & $\begin{array}{l}\text { Weighted labor } \\
\text { productivity }\end{array}$ & $\begin{array}{l}\% \text { change in } \\
\text { productivity }\end{array}$ \\
\hline Belgium & 113 & -1.47 & 121 & $+7 \%$ & 98 & $-14 \%$ \\
\hline Finland & 109 & 2.61 & 110 & $+1 \%$ & 86 & $-21 \%$ \\
\hline UK & 108 & 2.69 & 109 & $+1 \%$ & 85 & $-21 \%$ \\
\hline Austria & 107 & 1.72 & 109 & $+2 \%$ & 86 & $-20 \%$ \\
\hline Sweden & 101 & 2.65 & 102 & $+1 \%$ & 79 & $-22 \%$ \\
\hline Germany & 100 & 3.19 & 100 & — & 77 & $-23 \%$ \\
\hline Netherlands & 96 & -0.84 & 102 & $+7 \%$ & 79 & $-17 \%$ \\
\hline Denmark & 94 & 1.17 & 98 & $+4 \%$ & 74 & $-21 \%$ \\
\hline Spain & 87 & -2.41 & 96 & $+11 \%$ & 73 & $-16 \%$ \\
\hline Italy & 82 & -6.38 & 99 & $+20 \%$ & 75 & $-9 \%$ \\
\hline Greece & 65 & -10.53 & 88 & $+36 \%$ & 65 & - \\
\hline Portugal & 55 & -3.71 & 67 & $+21 \%$ & 44 & $-21 \%$ \\
\hline
\end{tabular}

Notes: Olley-Pakes decomposes weighted labor productivity into an unweighted productivity term and a (OP) covariance term. The counterfactuals maintain each country's own unweighted term constant and change the OP covariance term. Germany has the highest OP covariance in the sample and Greece the lowest OP. Data refers to the Total Industry, Market Services, and Construction sector (ISIC Rev.3 10-74). Data is calculated each year and then averaged for the 2004- 2009 period. Firm labor productivity is in USD Purchasing Power Parity (using OECD conversion rates) and normalized by Germany's productivity.

Source: SDBS Structural Business Statistics and author's calculations

Germany, respectively. In terms of percentage gains, Greece would increase its labor productivity by 36 percent, Italy and Portugal by 20 percent and 21 percent, respectively, and Spain by 11 percent.

The second counterfactual determines how much each country's weighted labor productivity would decrease if it had Greece's allocation of labor across firms (as measured by Greece's OP covariance term). Productivity losses that would occur from adopting Greece's allocation are between 9-23 percent. Such productivity losses would make all North Europe countries except Belgium less productive than actual Spain. ${ }^{16}$

The findings of this decomposition exercise confirm that improving the

\footnotetext{
${ }^{16}$ An alternative experiment, reported in Appendix A, finds how the weighted productivity index changes as weights change (as opposed to changing all of the OP covariance term). The results are similar: productivity gains of adopting the best distribution of employment shares in the sample are as large as 40 percent.
} 
allocation of labor across firms would go a long way of bridging cross-country TFP differences, even if the average firm productivity in a country remains constant. The next section proposes an explanation.

\subsection{Bankruptcy Efficiency: World Bank Doing Business Data}

This paper proposes that the recovery rate on loans made to bankrupt borrowers can by itself generate employment distributions that are consistent with those in the data. Figure 3 shows that more productive nations tend to have a higher recovery rate.

Figure 3: Bankruptcy Efficiency and Labor Productivity (2004-2009)

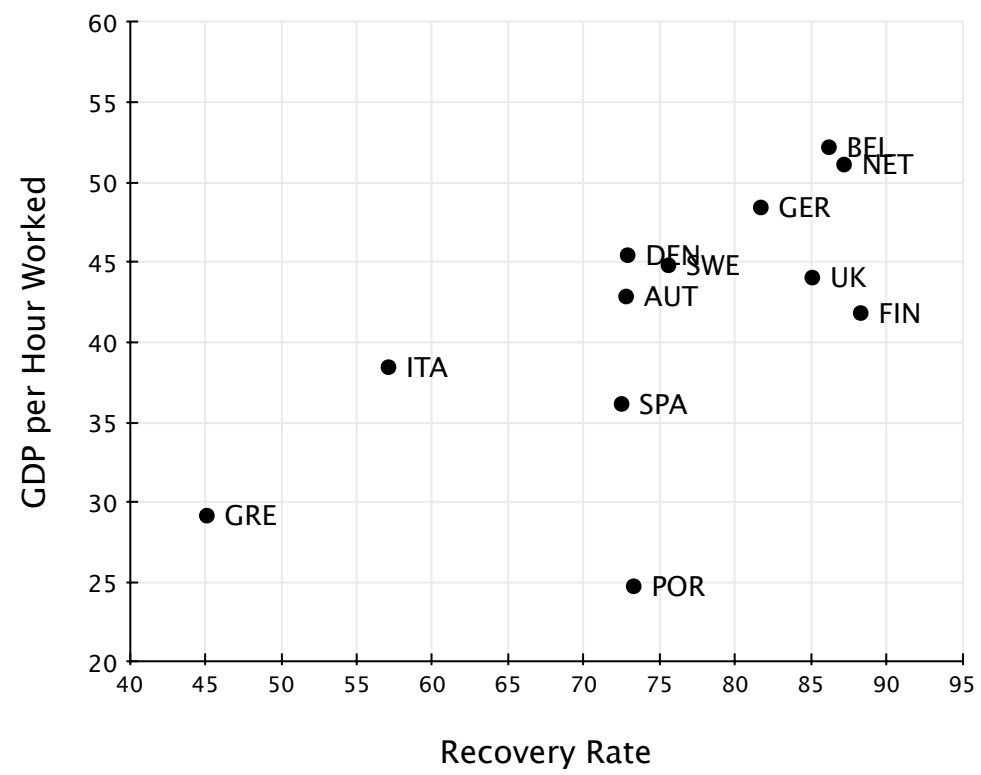

Notes: GDP per hour worked is in real 2005 USD. Recovery rate is cents on the dollar. Both statistics are averaged for the 2004-2009 period. The correlation is 0.65. Source: OECD Annual National Accounts and World Bank Doing Business.

The recovery rate is measured annually by the World Bank using a methodology developed by Djankov et al. (2008). The World Bank contacts bankruptcy lawyers in each country and sends them an identical case scenario of a company facing insolvency. The scenario is made as specific as possible, detailing type of company, size, location, and other factors. The company has a loan agreement with a domestic bank and is forced to default 
on its loan because of insolvency. The company also has assets (real estate property) valued at the same amount as the amount outstanding under the loan agreement. The bankruptcy lawyers are asked for their experience on the fraction of the outstanding loan that can be recovered by the bank. The recovery rate is the fraction of the loan recovered, in present value terms and net of legal costs. Lengthy resolution of legal proceedings, high legal costs and inefficient outcomes of the bankruptcy proceedings - liquidation rather than reorganization of a viable firm with temporary liquidity problems - all reduce the recovery rate measurement.

The following section sets up a model in which firm composition is endogenously generated by an exogenous recovery rate.

\section{Model}

The economy is populated by a continuum of financial intermediaries and a continuum of households of mass one.

Preferences and Endowments. Households are endowed with initial resources $\hat{f}$, one unit of labor and a production technology. Some households become entrepreneurs and operate their technology. Entrepreneurs employ capital and labor, produce a final good, and consume the profits. The remaining households become workers and rent their labor to entrepreneurs for the market wage $w$. Households have linear utility over consumption, $u(c)=c{ }^{17}$

Technology. Households are heterogeneous in entrepreneurial productivity $a_{i}$, where $i \in\{l o w, h i g h\}$, and have a production technology of the form,

$$
y_{i}=a_{i} k^{\alpha} n^{\gamma}, \quad \alpha, \gamma \in(0,1), \quad 0<\alpha+\gamma<1,
$$

with capital $k$ and labor $n$. A fraction $\nu$ of households are endowed with low entrepreneurial productivity $a_{\ell}$ and a fraction $1-\nu$ are endowed with high entrepreneurial productivity $a_{h}$. The costs of operating the technology include a fixed cost $f$. The need for financing arises because entrepreneurs cannot self-finance the fixed cost of production, $f>\hat{f}$.

\footnotetext{
${ }^{17}$ Linear utility has the advantage of delivering closed form solutions to the contract.
} 
Frictions. In the first-best scenario all agents pool their resources. Funding goes to the high-productivity agents first and any remaining funding goes to the low-productivity agents, given that they are profitable (i.e. their profits as entreprenuers are higher than their consumption as workers). Two frictions make first-best allocations unachievable. First, entrepreneurial productivity is the private information of the agents. Hence, low-productivity agents have an incentive to pretend to be high-productivity agents in order to improve their chances of obtaining funding.

Production occurs at the end of the period and is observable. Therefore, productivity levels can be inferred by common knowledge of the production function and observable inputs. First-best allocations could still be achieved with unbounded punishments for false reports. However, there is a second friction that limits repayments to a fraction $\phi$ of output. Bankruptcy is the scenario where output is less than the contractual repayment amount. Thus, in equilibrium, $\phi$ will be mapped to the bankruptcy recovery rate.

Financial Intermediaries. Financial intermediaries operate in a perfectly competitive market. ${ }^{18}$ Agents do not learn their type until after they have entered into the contract. This assumption avoids an adverse selection problem that might lead to non-existence of a unique financial intermediary. If households are heterogenous before they enter the contract, then competition between lenders might not lead to a pooling Nash equilibrium: a lender might always be able to offer a better contract for some borrowers (see Prescott and Townsend, 1984).

Timing. The timing of events, shown in Figure 4, is as follows:

1. Financial intermediaries post contracts. A contract is a 6 -tuple $\left\{\left(e_{\ell}, L_{\ell}, L_{\ell}^{F}\right)\right.$, $\left.\left(e_{h}, L_{h}, L_{h}^{F}\right)\right\}$. For each productivity type $i$, the contract specifies the fraction of entrepreneurs who will operate their technology, $e_{i}$. The rest (fraction $1-e_{i}$ ) work for a wage. For entrepreneurs who are chosen to operate their technology, the contract specifies the repayment schedule for true reports, $L_{i} \equiv L\left(a_{i} \mid a_{i}\right)$, and for false reports, $L_{i}^{F} \equiv L\left(a_{i} \mid a_{-i}\right)$.

\footnotetext{
${ }^{18}$ The assumption of perfect competition between financial intermediaries implies that intermediaries offer contracts that maximize the expected welfare of their pool of borrowers. Perfect competition could be replaced by an assumption of a few intermediaries engaging in Bertrand competition in contracts.
} 
Figure 4: Timing

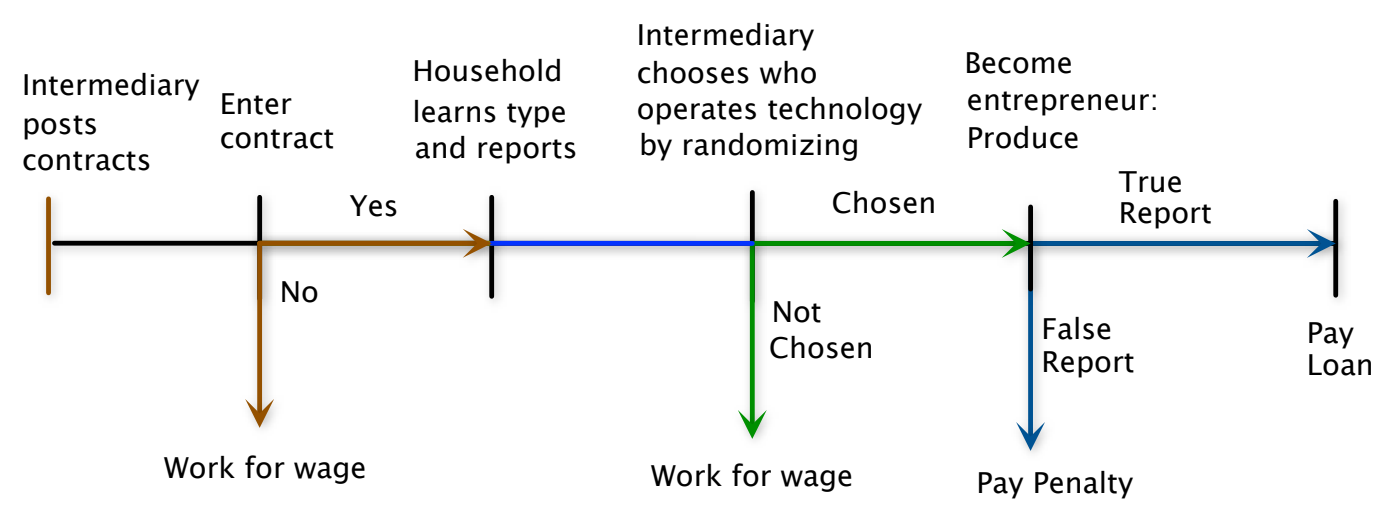

2. Households decide whether to enter the contract with the financial intermediary. Households who do not enter the contract work for a wage, obtain the market rate of return on their initial endowment, $\eta=(1+r) \hat{f}$, and consume $w+\eta$ at the end of the period.

3. Households learn their type and report it to the financial intermediary.

4. The financial intermediary chooses the households that will operate their technologies for each type (through a randomization device).

5. Households chosen to operate their technology become entrepreneurs and are allocated capital $k_{i}$, labor $n_{i}$, and fixed cost $f$. The households that are not chosen to operate their production technologies supply labor, earn the market wage rate and consume $w$.

6. Entrepreneurs produce and all information is revealed. Entrepreneurs who report truthfully consume $y_{i}-L_{i}$. Entrepreneurs who make false reports consume $y_{i}^{F}-L_{i}^{F}$.

Financial intermediaries maximize households' expected consumption subject to incentive compatibility, enforcement, participation, and resource feasibility constraints, as described below.

The Intermediary's Problem. The revelation principle allows us to focus, without loss of generality, on allocations in which households report their 
type truthfully. The objective of the financial intermediary is to choose allocations $\left(k_{\ell}, n_{\ell}, k_{h}, n_{h}\right)$ and terms of contract $\left(e_{\ell}, L_{\ell}, L_{\ell}^{F}, e_{h}, L_{h}, L_{h}^{F}\right)$, given prices $w$ and $r$ that solve the following problem.

1. Objective Function: Entrepreneur's expected consumption is maximized (before they learn their type),

$$
\max \mathbb{E}[c]=\nu c_{\ell}+(1-\nu) c_{h}
$$

where $c_{i}=e_{i}\left(y_{i}-L_{i}\right)+\left(1-e_{i}\right) w$. The consumption considered by the lender is that of those who enter the contract, so it does not include endowment $\eta$. Since intermediaries can achieve any allocation that households can achieve on their own, and since the intermediary maximizes household's expected utility, households are weakly better off contracting with the intermediary. ${ }^{19}$

2. Incentive Compatibility:

$$
e_{i}\left(y_{i}-L_{i}\right)+\left(1-e_{i}\right) w \geq e_{-i}\left(y_{i}^{F}-L_{i}^{F}\right)+\left(1-e_{-i}\right) w, \quad \forall i \in\{\ell, h\} .
$$

A type $i$ entrepreneur who falsely claims to be type $-i$ will operate his or her productive technology with probability $e_{-i}$ and be assigned capital $k_{-i}$, labor $n_{-i}$, and fixed cost $f$. With these inputs, the type $i$ entrepreneur will produce $y_{i}^{F}=\frac{a_{i}}{a_{-i}} y_{-i}$ (derivation in Appendix C).

3. Imperfect Enforcement: Repayments can be collected up to a fraction $\phi$ of revenues.

$$
\begin{aligned}
L_{i} & \leq \phi y_{i}, \quad \forall i \in\{\ell, h\} \\
L_{i}^{F} & \leq \phi y_{i}^{F}, \quad \forall i \in\{\ell, h\}
\end{aligned}
$$

4. Participation Constraint: If a household declines to enter a contract, he or she gets wage $w$, and consumes the wage plus his net worth for a total consumption of $w+\eta$. Therefore, the participation constraint is

$$
\nu c_{\ell}+(1-\nu) c_{h} \geq w+\eta \text {. }
$$

5. Feasibility:

\footnotetext{
${ }^{19}$ The intermediary can match the outside option by setting $e_{h}=e_{\ell}=0$ and returning the initial endowment to households.
} 
The financial intermediary faces a known fraction $\nu$ of low-productivity entrepreneurs and a fraction $(1-\nu)$ of high-productivity entrepreneurs. Let $\kappa_{i} \equiv r k_{i}+w n_{i}+f$ stand for the cost of producing output $y_{i}$. The feasibility constraint requires that the resources the financial intermediary disburses to entrepreneurs (left-hand side) cannot exceed collections plus initial resources (right-hand side),

$$
\nu e_{\ell} \kappa_{\ell}+(1-\nu) e_{h} \kappa_{h} \leq \nu e_{\ell} L_{\ell}+(1-\nu) e_{h} L_{h}+\eta \text {. }
$$

In a direct mechanism the financial intermediary allocates output, capital and labor directly to firms. It is helpful to work directly with repayment amount $L_{i}$, but this amount can be mapped to interest rates on a loan of size $r k_{i}+w n_{i}+f$. Randomizing over projects is not necessary to separate types, but it improves welfare as it convexifies the occupational-choice problem of households. Thus, other contract spaces might be able to separate types, but doing so would be sub-optimal to a contract space that contains randomizations $e_{\ell}$ and $e_{h}$.

\subsection{Partial Equilibrium: Optimal Contract}

Allocations. The intermediary allocates the profit-maximizing levels of capital and labor to each operating enterprise, given prices $r$ and $w$. This is so because the objective of the intermediary is equivalent to a social planner problem, so the intermediary will try to distort as few margins as possible. Therefore $k_{i}=k_{i}^{*}$ and $n_{i}=n_{i}^{*}$. The implication of optimal firm size is that the marginal product of capital and the marginal product of labor are equated across firms, and hence there is no misallocation of inputs across existing firms. To simplify notation from here on, $y_{i}, k_{i}$, and $n_{i}$ stand for their profit maximizing levels $y_{i}^{*}, k_{i}^{*}$ and $n_{i}^{*}$.

Terms of the contract. The following proposition states partial-equilibrium properties of the contract.

Proposition 1. Suppose wages are low enough that the no-private-information allocation is not incentive compatible, $w<\frac{a_{\ell}}{a_{h}} y_{h}-\phi \kappa_{\ell}$.

i. Average firm productivity: The ratio of high-productivity to lowproductivity projects funded is given by the expression

$$
\frac{e_{h}}{e_{\ell}}=\frac{y_{\ell}-L_{\ell}-w}{(1-\phi) \frac{a_{\ell}}{a_{h}} y_{h}-w} .
$$


ii. Quantity: The quantity of high-productivity projects funded is given by the expression

$$
e_{h}=\frac{\eta}{\nu\left(\kappa_{\ell}-L_{\ell}\right)\left(\frac{(1-\phi) \frac{a_{\ell}}{a_{h}} y_{h}-w}{y_{\ell}-L_{\ell}-w}\right)+(1-\nu)\left(\kappa_{h}-\phi y_{h}\right)}
$$

iii. Furthermore, suppose wages are high enough so that low-productivity projects are not profitable, $w>y_{\ell}-\kappa_{\ell}$. Then $L_{\ell}=0$, and the average firm productivity (9) and the quantity of high-productivity projects (10) are strictly increasing in the recovery rate $\phi$.

Proof. For i. and ii. see Appendix D. For iii., if $L_{\ell}=0$ then $\frac{\partial\left(e_{h} / e_{\ell}\right)}{\partial \phi}>0$ and $\frac{\partial e_{h}}{\partial \phi}>0$ in (9) and (10), respectively.

Expression (9) is obtained by combining the binding incentive compatibility constraint for low-productivity agents with maximum punishment for false reports, $L_{\ell}^{F}=\phi y_{\ell}^{F}$, and replacing $y_{\ell}^{F}=\frac{a_{\ell}}{a_{h}} y_{h}$. Expression (10) is obtained by combining expression (9) with the feasibility constraint and maximum collection from high-productivity projects, $L_{h}=\phi y_{h} \cdot{ }^{20}$ The assumption of an upper threshold for wages is simply a formalization of the initial premise that private information is a constraint on lenders' funding decisions. If wages are too high, low-productivity entrepreneurs are better off renting their labor than they are operating their technologies. In that scenario they have no incentive to misreport their types as they prefer a lower probability of operating their technologies, and information constraints do not bind.

The first part of Proposition 1 expresses the ratio of high-productivity to low-productivity projects. If low-productivity projects are unprofitable, then this ratio decreases as the level of contract enforceability decreases. The intuition is that, as the ability to punish for false reports shrinks, the lender has to increase the relative probability of acceptance of low-productivity projects in order to prevent low-types from reporting falsely. Notice this "average firm productivity" effect goes solely through the incentive compatibility of low-productivity agents. The second part of Proposition 1 shows the expression for the total quantity of high-productivity projects. If low-productivity

\footnotetext{
${ }^{20}$ Incentive compatibility for high-productivity agents might bind, in which case $L_{h}$ is set by the binding incentive compatibility constraint for high-productivity agents. This is in contrast to Erosa and Hidalgo-Cabrillana (2008); see Appendix D for details.
} 
projects are unprofitable, the expression increases with the recovery rate. This effect comes from the feasibility constraint. As the recovery rate increases, the lender is able to extract higher rents from profitable projects (right-hand side of (8) increases) in order to fund other profitable projects (left-hand side of (8) increases).

The assumption of unprofitability of low type is a sufficient but not necessary condition to obtain clean predictions for the change in average firm productivity and total quantity with recovery rates. If low-productivity entrepreneurs are profitable, the average productivity and quantity of projects could still increase, depending on model parameters. However, the quantitative exercise in Section 5, which imposes no restrictions on parameters, verifies that all conditions and assumptions hold.

\subsection{Total Factor Productivity}

Define $\pi_{\ell} \equiv \nu e_{\ell}$ and $\pi_{h} \equiv(1-\nu) e_{h}$ as the measure of low-productivity and high-productivity projects operated in the economy, respectively. Let $Y \equiv \sum_{i} \pi_{i} y_{i}, K \equiv \sum_{i} \pi_{i} k_{i}$, and $N \equiv \sum_{i} \pi_{i} n_{i}$ be the aggregate ouput, capital and labor in the economy, respectively. The following proposition states that TFP is increasing in the recovery rate through the weights of the firm-size distribution, $e_{\ell}$ and $e_{h}$.

Proposition 2. $\quad i$. The aggregate production function has a closed-form solution given by

$$
Y=A K^{\alpha} N^{\gamma}
$$

where TFP is

$$
A \equiv\left(\nu e_{\ell} a_{\ell}^{\frac{1}{1-\alpha-\gamma}}+(1-\nu) e_{h} a_{h}^{\frac{1}{1-\alpha-\gamma}}\right)^{1-\alpha-\gamma}
$$

Measured TFP in the competitive equilibrium is

$$
\frac{Y}{K^{\frac{\alpha}{\alpha+\gamma}} N^{\frac{\gamma}{\alpha+\gamma}}}=Y^{\frac{\alpha+\gamma-1}{\alpha+\gamma}} A^{\frac{1}{\alpha+\gamma}}
$$

ii. TFP is strictly increasing in the quantity of high-productivity projects $e_{h}$. In addition, if $(1-\nu) a_{h}^{\frac{1}{1-\alpha-\gamma}}>\nu a_{\ell}^{\frac{1}{1-\alpha-\gamma}}, T F P$ is strictly increasing in the average quality of projects $e_{h} / e_{\ell}$, as long as $e_{\ell}+e_{h}$ is simultaneously non-decreasing. 
Proof. For i., see Appendix B. ii. follows from (12).

For a non-decreasing total quantity of projects, as the recovery rate increases, TFP increases if the quantity of low-productivity projects does not decrease faster than the increase in high-productivity projects. In the quantitative exercise, both high-productivity projects and low-productivity projects increase with the recovery rate.

$A$ is not the same as measured TFP. In level accounting exercises the aggregate production function is assumed to display constant returns to scale with capital share equal to $1 / 3$. Since firms in the model have decreasing returns to scale, equation (13) is the correct expression to compare to the data in the quantitative section, with $\frac{\alpha}{\alpha+\gamma}$ set to $1 / 3$.

\subsection{Competitive Equilibrium}

With the household's and intermediary's problem specified, the competitive equilibrium in this economy can now be defined. Aggregate labor supply is determined by the measure of households who did not become entrepreneurs, $\nu\left(1-e_{\ell}\right)+(1-\nu)\left(1-e_{h}\right)$. Aggregate labor demand is given by the total amount of labor demanded by firms, $\nu e_{\ell} n_{\ell}+(1-\nu) e_{h} n_{h}$. Similarly aggregate capital demand and aggregate final good supply are determined by $\nu e_{\ell} k_{\ell}+(1-\nu) e_{h} k_{h}$ and $\nu e_{\ell} y_{\ell}+(1-\nu) e_{h} y_{h}$, respectively. Capital is supplied by external sources, $K$. Finally, aggregate final good demanded is determined by the residual consumption from the household's problem, $c^{e}=\nu\left[e_{\ell}\left(y_{\ell}-L_{\ell}\right)+\left(1-e_{\ell}\right) w\right]+(1-\nu)\left[e_{h}\left(y_{h}-L_{h}\right)+\left(1-e_{h}\right) w\right]$.

Definition 1. A competitive equilibrium consists of a financial contract $\left\{e_{i}, L_{i}, L_{i}^{F}\right\}_{i}$, allocations $\left\{y_{i}, k_{i}, n_{i}\right\}_{i}$ and prices $w$ and $r$ such that

1. Allocations $k_{i}, n_{i}$ and $y_{i}$ maximize firms' profits, given prices $w$ and $r$ for all $i$

2. The financial contract solves the financial intermediary's problem

3. Markets Clear:

- $w$ clears the labor market: $\nu e_{\ell} n_{\ell}+(1-\nu) e_{h} n_{h}=\nu\left(1-e_{\ell}\right)+(1-$ $\nu)\left(1-e_{h}\right)$

- Given $r$, the capital market clears: $\nu e_{\ell} k_{\ell}+(1-\nu) e_{h} k_{h}=K$

- The final goods market clears: $\mathbb{E}[c]+f\left(\nu e_{\ell}+(1-\nu) e_{h}\right)=\nu e_{\ell} y_{\ell}+$ $(1-\nu) e_{h} y_{h}$ 
General equilibrium effects reinforce the misallocation of resources at low levels of bankruptcy efficiency. With better bankruptcy efficiency, there is higher labor demand which drives up wages and relaxes the incentive compatibility constraint of low-productivity agents by making entrepreneurs' outside option more attractive. (Higher wages relax $(4)$ since $\left.\left(1-e_{\ell}\right)>\left(1-e_{h}\right)\right)$.

With the description of the model complete, Section 4 discusses how the model is taken to the data.

\section{Taking the Model to the Data: Multi-Sector Model}

An important set of parameters in the calculation of TFP are the levels of firm productivity, $a_{\ell}$ and $a_{h}$. The first-order conditions for the firm problem show a direct relationship between the employment distribution and the distribution of productivity. In particular,

$$
\frac{n_{h}}{n_{\ell}}=\left(\frac{a_{h}}{a_{\ell}}\right)^{\frac{1}{1-\alpha-\gamma}}
$$

In order to calibrate the distribution of productivities one could arbitrarily divide the U.S. firm-size distribution into a representative large firm and a representative small firm and use equation (14). Alternatively, one can extend the model in some direction to obtain a distribution of firm sizes. The approach I use here is to extend the model to the case of multiple sectors and show that the main results for a single sector hold in this more general framework. ${ }^{21}$

Preferences, production functions, and frictions are the same as in the one-sector economy. A sector in the model is a group of firms that produce an identical product. There is a unit mass of agents born into each sector. Agents are born with a sector-specific technology but they can work in any sector for a wage $w$, that is the same across sectors. Sectors differ in the level of fixed cost that are involved in operating a technology. There is one intermediary per sector (no cross-subsidization across sectors), so the

\footnotetext{
${ }^{21}$ Another approach is to stick to one sector and have a full distribution of productivities. Although possible in theory, this approach raises a set of unnecessary complications: the number of possible incentive-compatibility deviations to check increases exponentially with number of types, which forces the use of tools such as the first-order approach (as in Rogerson, 1985), for which concave utility is usually a necessary condition.
} 
contract of the one-sector economy can be viewed as the contract of a specific sector.

Let subscript $j$ be the sector subscript and $i$ be the productivity level subscript. To redefine the problem with multiple sectors, rewrite individual production functions as

$$
y_{i j}=a_{i} k_{i j}^{\alpha} n_{i j}^{\gamma}
$$

A firm's problem is

$$
\max _{k_{i j}, n_{i j}} p_{j} y_{i j}-r k_{i j}-w n_{i j}-f_{j},
$$

where $p_{j}$ are sector-specific output prices. Let $\pi_{\ell j} \equiv \nu e_{\ell j}$ and $\pi_{h j}=(1-$ $\nu) e_{h j}$ stand for the measure of low and high-productivity projects in sector $j$, respectively. Using the aggregation in Appendix $\mathrm{B}$, each sector has a representative firm with a production function of the form

$$
y_{j}=A_{j} k_{j}^{\alpha} n_{j}^{\gamma}
$$

where $y_{j}=\sum_{i} \pi_{i j} y_{i j}, k_{j}=\sum_{i} \pi_{i j} k_{i j}, n_{j}=\sum_{i} \pi_{i j} n_{i j}$, and $A_{j} \equiv\left(\sum_{i} \pi_{i j} a_{i}^{\frac{1}{1-\alpha-\gamma}}\right)^{1-\alpha-\gamma}$. The representative sector firm solves the following problem

$$
\max _{k_{j}, n_{j}} p_{j} y_{j}-r k_{j}-w n_{j} .
$$

The fixed cost shows up as a cost in the firm problem but not in the representative sector firm problem. Finally, I introduce a new parameter, $\theta$, which determines the complementarities between sectors. In particular, I assume that a perfectly competitive representative firm produces a single final good by combining sector outputs with a CES technology, so that it solves the problem

$$
\max _{\left\{y_{j}\right\}}\left(\sum_{j} y_{j}^{\theta}\right)^{1 / \theta}-\sum_{j} p_{j} y_{j}
$$

where $\frac{1}{1-\theta}$ is the elasticity of substitution between sectors.

The main difference from the one-sector competitive equilibrium is that there are now $J$ new market-clearing conditions, one for each sector. 
Definition 2. A competitive equilibrium with sectors consists of financial contracts $\left\{c_{i j}, e_{i j}, L_{i j}, L_{i j}^{F}\right\}_{i j}$, allocations $\left\{n_{i j}, k_{i j}, y_{i j}\right\}_{i j}$ and prices $w, r$, and $\left\{p_{j}\right\}_{j}$ such that

1. $k_{i j}$ and $n_{i j}$, and $y_{i j}$ solve the firm's problem, $\forall i, j$;

2. The financial contract solves the financial intermediaries problem, $\forall j$;

3. Markets Clear:

- $p_{j}$ clears the sector market, $y_{j}^{\text {Supply }}\left(p_{j}, r, w\right)=y_{j}^{\text {Demand }}\left(p_{j},\left\{c^{e}\right\}\right)$ $\forall j$;

- $w$ clears the labor market, $\sum_{j} \sum_{i} \pi_{i} n_{i j}=\sum_{j}\left[\nu\left(1-e_{l j}\right)+(1-\right.$ $\left.\nu)\left(1-e_{h j}\right)\right] ;$

- Given $r$, the capital market clears: $\sum_{j} \sum_{i} \pi_{i} k_{i j}=K$;

- The final goods market clears, $\sum_{j} \mathbb{E}\left[c_{j}\right]+\sum_{j} f_{j}\left(\nu\left(1-e_{l j}\right)+(1-\right.$ $\left.\nu) e_{h j}\right)=\left(\sum_{j} y_{j}^{\theta}\right)^{1 / \theta}$

where $y_{j}^{\text {Supply }}$ is output by sector $j, y_{j}^{\text {Demand }}$ is demand by the final good producer.

Proposition 3. TFP in the multi-sector economy with sectors is analogous to the single-sector economy. In particular,

$$
\frac{Y}{K^{\frac{\alpha}{\alpha+\gamma}} N^{\frac{\gamma}{\alpha+\gamma}}}=\left(\sum_{j}\left(y_{j}^{\frac{\alpha+\gamma-1}{\alpha+\gamma}} A_{j}^{\frac{1}{\alpha+\gamma}}\right)^{\frac{\theta}{1-\theta}}\right)^{\frac{1-\theta}{\theta}}
$$

where

$$
A_{j} \equiv\left(\nu e_{\ell j} a_{\ell}^{\frac{1}{1-\alpha-\gamma}}+(1-\nu) e_{h j} a_{h}^{\frac{1}{1-\alpha-\gamma}}\right)^{1-\alpha-\gamma}
$$

Proof. See Appendix E.

\section{Quantitative Analysis}

In this section I calibrate the model to data for the United States. In the calibration I treat the United States as an economy with private information and imperfect enforcement frictions, and with a recovery rate of 80 percent. 
With the calibrated economy in place, I vary the recovery rate as in the data in order to determine how the United States' productivity would change if it had other countries' recovery rates.

\subsection{Calibration and Measurement}

Several of the model parameters are those of the standard growth model and I follow standard procedures for choosing those values. Relative to the growth model, what is new are the parameters that determine the distribution of firms in equilibrium. Tables 3 and 4 summarize the calibration.

Table 3: Benchmark Calibration to U.S. Data: Parameters Set Before Equilibrium

\begin{tabular}{rlcl}
\hline Symbol & Definition & Value & Target/Source \\
\hline$\phi$ & Recovery Rate & $80 \%$ & U.S. recovery rate \\
$\alpha$ & Firm Capital Share & $28.3 \%$ & Agg. Capital Share, Dec. Returns \\
$\gamma$ & Firm Labor Share & $56.7 \%$ & Agg. Capital Share, Dec. Returns \\
$\theta$ & Complementarity between Sectors & 0.9 & Markup of 11\% \\
$J$ & Number of Sectors & 36 & Rajan and Zingales (1998) \\
{$\left[f_{1}, f_{36}\right]$} & Range of Fixed Costs & {$[1,4.3]$} & Rajan and Zingales (1998) \\
$a_{\ell}$ & Productivity of Low Type & 1 & Normalization \\
\hline
\end{tabular}

Table 4: Benchmark Calibration to U.S. data: Parameters Calibrated to Equilibrium Outcomes

\begin{tabular}{|c|c|c|c|c|c|}
\hline Symbol & Definition & Value & Target Moments & U.S. Data & Model \\
\hline$r$ & Interest Rate & $10 \%$ & Capital Output Ratio & $\sim 3$ & 3.12 \\
\hline$a_{h}$ & Productivity of High Type & 1.695 & Top $10 \%$ employment share & $65 \%$ & $65 \%$ \\
\hline$\nu$ & Fraction of Low Type & $63 \%$ & Skew of firm-size distribution & 5.05 & 4.99 \\
\hline$\eta$ & Initial endowment & 0.376 & Mean firm size & 50.5 & 50.5 \\
\hline
\end{tabular}

I first discuss the choice of parameters for which direct estimates exist, followed by those chosen to match equilibrium moments. The data on recovery rate is collected from the World Bank Doing Business database. I use the average from 2004 (the earliest available data) to 2009 (to exclude the financial crisis). The recovery rate is $\phi=80 \%$ for the United States.

The extent of decreasing returns in the production function is an important parameter in the analysis. Direct estimates of firm-level production func- 
tions and several calibration procedures point to a value for $\alpha+\gamma=0.85 .^{22}$ The split between $\alpha$ and $\gamma$ is done according to the income share of capital and labor, so I assign $1 / 3$ to capital and $2 / 3$ to labor, implying $\alpha=0.283$ and $\gamma=0.567 .{ }^{23}$

Sector outputs are aggregated with a CES function with elasticity parameter $\frac{1}{1-\theta}$. TFP differences are magnified by the degree of complementarity between sectors, so I am conservative in the choice of this parameter and choose $\theta=0.9$. In a model of monopolistic competition this choice would deliver a markup of 11 percent, a lower bound among the empirical estimates of markup costs. ${ }^{24}$

The number of sectors and the sector-specific fixed cost are based on values provided by Rajan and Zingales (1998). Using Compustat data, Rajan and Zingales calculate the need for external finance (defined as the fraction of capital expenditures that is not financed with cash flow from operations) for thirty-six sectors in the United States. The sector with lowest need for external finance is Tobacco, with a measure of -0.45 and the one with the highest need is Drugs at 1.49. I set $J=36$ and normalize the lowest level of sector fixed cost to 1 . Sector fixed costs are chosen to range uniformly from 1 to $(0.45+1.49) / 0.45=4.3$. To place the magnitude of fixed costs in perspective, consider that the wage in the competitive equilibrium is around 1.05. Therefore, fixed costs of starting a firm are about 1 to 4.3 times the average annual salary.

The model period is one year. The interest rate is set to $10 \%$ to match a capital output ratio of 3 . This is consistent with evidence in Gomme and Rupert (2007). I am left with four parameters to match to equilibrium targets: $a_{\ell}, a_{h}, \nu$ and $\eta$. Any choice of $a_{\ell}$ can be undone by rescaling $a_{h}$, so I set $a_{\ell}=1$ as a normalization. The other parameters are calibrated to moments of the U.S. firm-size distribution.

The data for the U.S. firm-size distribution is from the US Census Bureau, which reports the number of establishments for certain employment

\footnotetext{
${ }^{22}$ See, for example, Basu and Fernald (1995), Atkeson and Kehoe (2005), and Amaral and Quintin (2010).

${ }^{23}$ Using labor shares, Gollin (2002) shows that capital shares are close to $1 / 3$ for different countries and do not systematically vary with development levels.

${ }^{24}$ This value is in line with the choice in Atkeson and Kehoe (2005), and the evidence in Basu and Fernald (1995), Basu (1996) and Basu and Kimball (1997).
} 
ranges for all sectors at the three-digit level. ${ }^{25}$ I restrict the observations to manufacturing to make it compatible with Rajan and Zingales (1998) fixedcost data. I set $a_{h}$ to match the share of employment by the top 10 percent of the largest firms. I set $\nu$, to match a mean to median firm size ratio of 5.05. The endowment $\eta$ shifts the firm-size distribution, so it is set to match the average firm size in U.S. manufacturing of $50.5 .^{26}$

\section{Findings}

\subsection{Variation in the recovery rate, $\phi$}

I begin by describing how employment shares and the firm-size distribution vary with the recovery rate. Large firms in the model are those of high-productivity in each sector, $\pi_{h j}$, which are also the largest firms overall. Figure 5 plots the employment share of large firms. In the model, the employment share of large firms is $N_{h} \pi_{h} /\left(N_{\ell} \pi_{\ell}+N_{h} \pi_{h}\right)$, with $\pi_{h}=\sum_{j} \pi_{h j}$. The match of this statistic in the data is the employment share of firms larger than the average firm size of fifty employees. Figure 5 shows that employment shares by large firms drops from 83 percent in the benchmark to 64 percent when the recovery rate is at 45 percent, which is Greece's recovery rate. Figure 6 plots the proportion of large firms in the economy, $\pi_{h} /\left(\pi_{\ell}+\pi_{h}\right)$. The figure shows that the proportion of large firms drops from 13 percent in the benchmark to 5 percent. ${ }^{27}$

Figures 7 and 8 describe how the change in emploment shares and firmsize distribution affect aggregate TFP and labor productivity, respectively. Figure 7 shows that TFP can drop up to 30.7 percent if recovery rates vary from 80 cents on the dollar to 45 cents on the dollar. The convexity of the TFP function, which is inherited from the convexity of the "proportion of large firms" function, suggests that the explanatory power of recovery rates

\footnotetext{
${ }^{25}$ Given that the Lucas span of control framework is a theory of establishments, not an enterprise-level theory, it is important to use establishment data for the quantitative exercise. I thank an anonymous referee for this observation. Establishment data is publicly available for the U.S. but, unfortunately, not for European countries.

${ }^{26}$ From U.S. Census data I only observe the number of establishment for certain employment ranges. The mean employment size for each range is used to compute the mean firm size.

${ }^{27}$ Notice that Figures 5 and 6 are the model equivalents to Figures 1 and 2 in Section 2.1 .
} 
Figure 5: Employment Share of Large

Firms

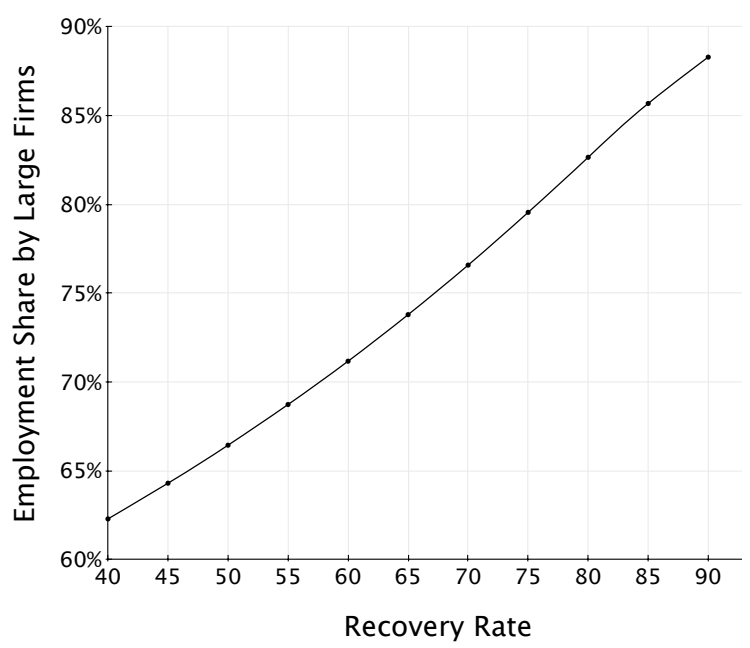

Figure 6: Proportion of Large Firms

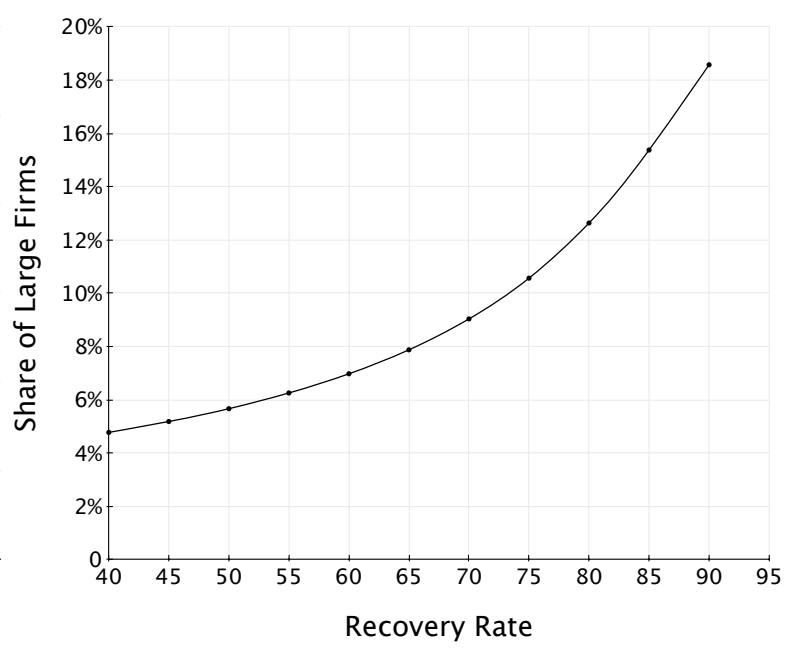

Notes: (Left) The employment share of large firms is calculated as $N_{h} \pi_{h} /\left(N_{\ell} \pi_{\ell}+N_{h} \pi_{h}\right)$. (Right) The proportion of large firms is calculated as $\pi_{h} /\left(\pi_{\ell}+\pi_{h}\right)$.

increases with income; that is, differences in bankruptcy efficiency generate greater differences in TFP among high-income countries.

Figure 8 plots aggregate labor productivity, which drops by 47.8 percent when recovery rates go from 80 cents on the dollar to 45 cents on the dollar. Aggregate labor productivity varies significantly more than aggregate TFP across countries in the data - a variation the model captures - because labor productivity captures variations not only in TFP but also in capital labor ratios. Capital labor ratios decrease with the recovery rate because lower recovery rates imply lower wages. Since capital rental rates are constant, firms substitute labor for capital. ${ }^{28}$

\footnotetext{
${ }^{28}$ Appendix F presents an alternative specification where the parameter governing truthful repayments is different from that governing false report repayments and only false repayment vary with the recovery rate.
} 
Figure 7: TFP and Recovery Rate

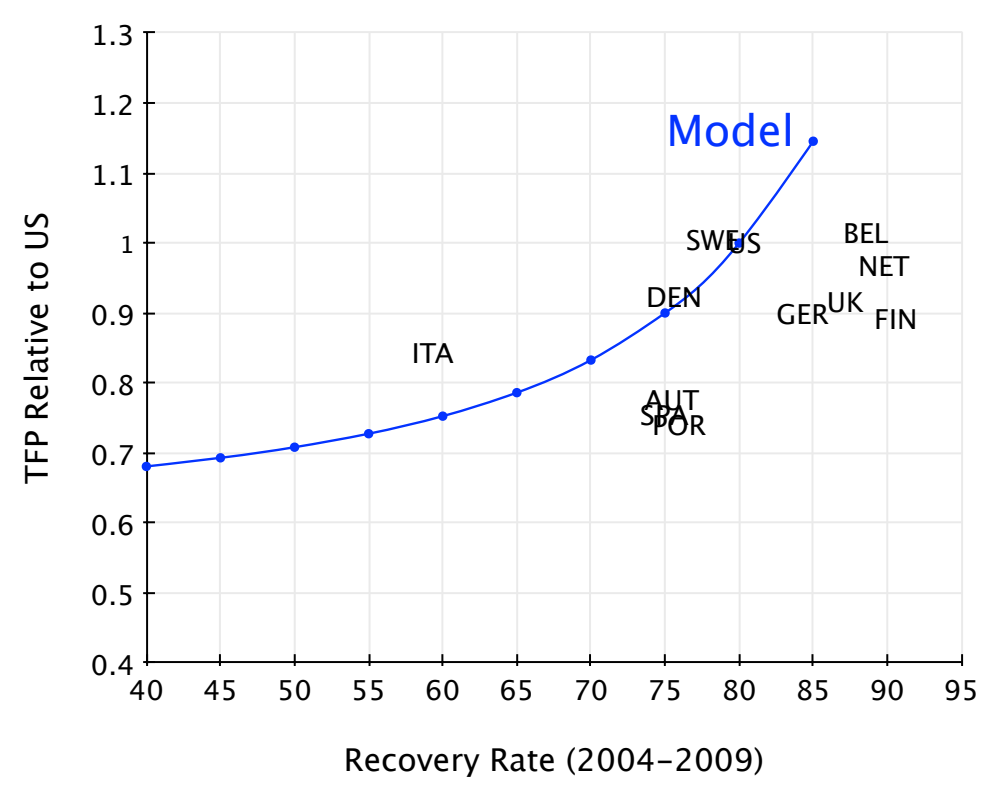

Notes: Data TFP is calculated from GGDC (1997 levels) and AMECO (growth rates). Data for Greece is missing on the GGDC.

\section{Evidence From Bank Loan Portfolios Across Countries}

The European Central Bank compiles data of new bank loans across countries that help check consistency of the model with data along another dimension. A commonly used proxy of the level of financing to small and medium-sized firms (SMEs, firms with less than 250 employees) in OECD countries are new loans of EUR 1 million or less. ${ }^{29}$ Consistent with the model implications, Figure 9 shows that the proportion of new loans that are of value less than EUR 1 million is greater for countries with a low recovery rate. $^{30}$

\footnotetext{
${ }^{29}$ See OECD (2012).

${ }^{30}$ Of course, based on this graph alone, causality could run both ways. That is, it could be possible that banks lend proportionally more to small firms in poorer countries precisely because there are more small firms for reasons other than financing needs. However, it is reassuring for the theory in this paper that this correlation exists, as there are reasons
} 
Figure 8: Labor Productivity and Recovery Rate

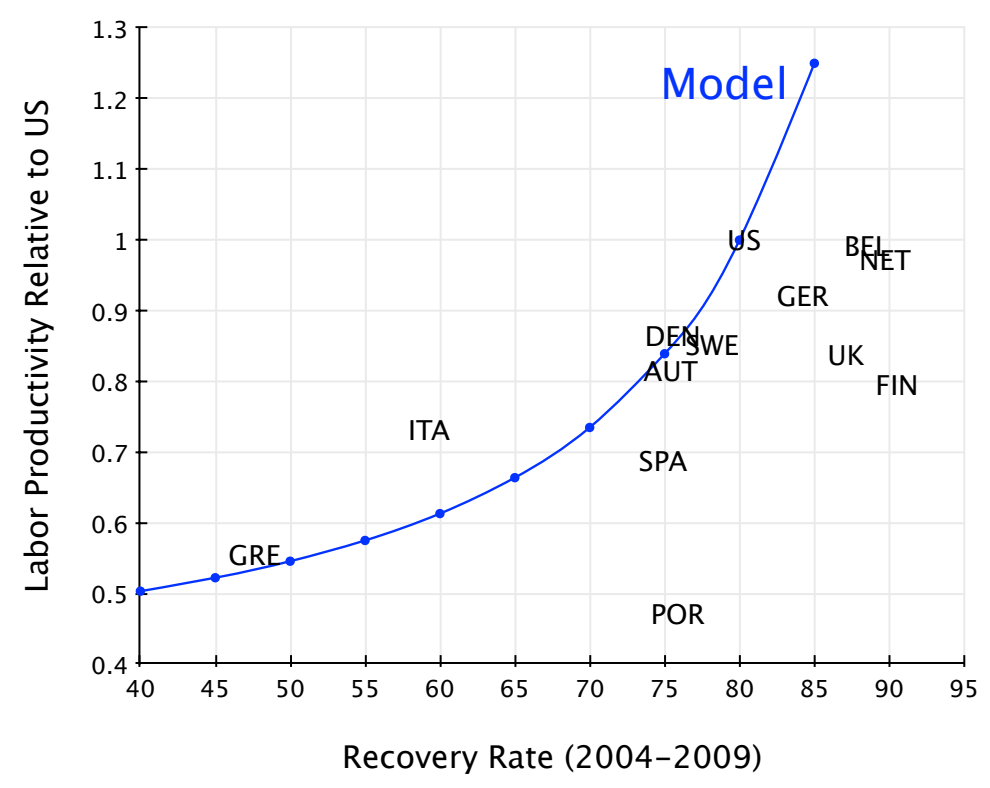

\section{Conclusion}

This paper documents that the employment share of large firms is an important driver of productivity differences among OECD countries, and it proposes differences in bankruptcy efficiency as a driver of these shares. Low recovery rates, a measure of bankruptcy efficiency, affect productivity by shifting the selection of firms towards less productive firms and reducing the number of firms in an economy. The model calibrated to U.S. data suggests that differences in the recovery rate alone can generate labor productivity and differences in TFP of similar magnitudes of those observed across OECD countries.

The model in this paper is deliberately kept simple so as to present, as transparently as possible, a channel by which bankruptcy policy affects ag-

why it might run in the opposite direction. For example, countries with high recovery rates also tend to have more liquid bond markets (Becker and Josephson, 2016). As long as larger firms resort more to bonds in countries with high recovery rates, they might also depend proportionately less on bank loans. 
Figure 9: Percentage of New Bank Loans Allocated to SMEs

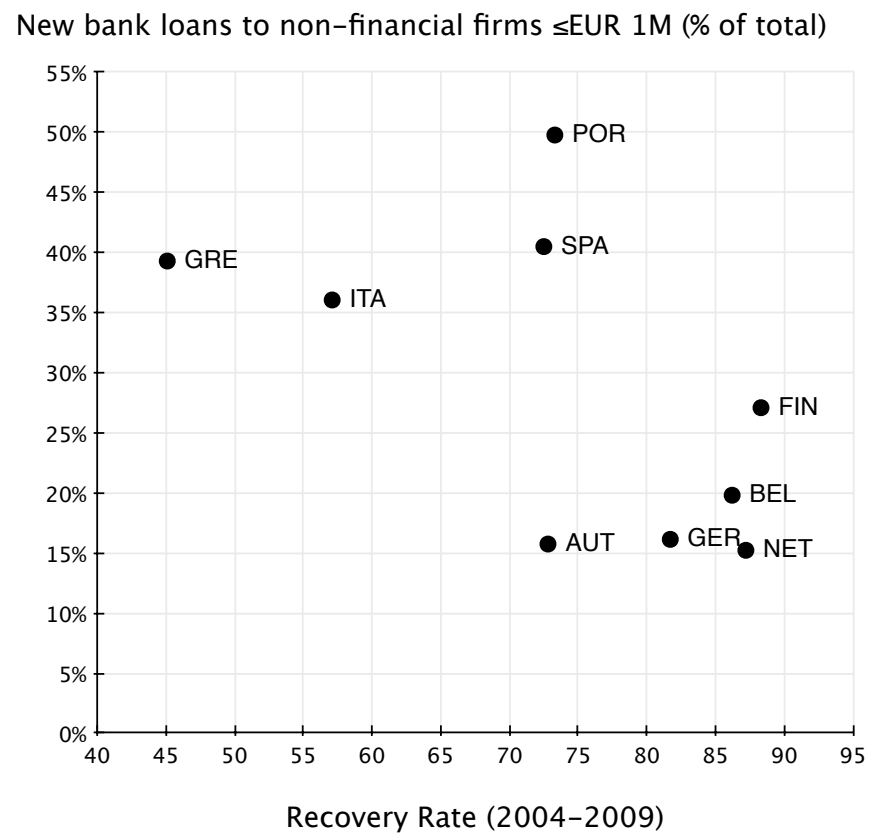

Notes: The statistic represents the proportion of new loans to non-financial firms of EUR $1 \mathrm{M}$ or less, a proxy for loans to SMEs. New loans are loans other than revolving loans, overdrafts, convenience and extended credit card debt loans to non-financial corporations. The statistic is calculated for every period and averaged for 2004-2009. ECB data is only for Eurozone members, so it excludes Denmark, the United Kingdom, and Sweden from the original sample. The correlation is -0.56 .

Source: European Central Bank and World Bank Doing Business.

gregate productivity. In order to do this, the model abstracts from savings decisions, both by households and firms. It is not clear whether endogenous savings would dampen or amplify the cross-country TFP differences attributed to bankruptcy policy. Savings would dampen TFP differences across countries if firms and households can save themselves out of borrowing constraints. However, if households in poor countries are not able to save enough to overcome borrowing constraints, TFP differences across countries would be amplified. Exploring the impact of savings on the channel presented in this paper would be interesting future work.

A related point is that the model attributes all differences in employ- 
ment shares to differences in bankruptcy procedures. However, other policies might also help explain the prevalence of small firms in poorer countries. Examples include taxation, onerous regulation, poor transportation and communication infrastructure, and lack of flexible labor markets. These alternative sources of distortions might complement or substitute for the role of bankruptcy in shaping firm-size distributions. Future work could look at disentangling the effect of the competing sources of firm-size distributions. Work that helps measure these forces directly in a way that makes them comparable across countries would be very helpful in understanding their impact on differences on aggregate productivity and income.

\section{Appendix A. Additional Tables}

Table A-1: Correlations by Sector (2004-2009)

\begin{tabular}{lcc}
\hline & $\begin{array}{c}\text { Correlation between } \\
\text { Employment Share by Large Firms } \\
\text { and Agg. Productivity }\end{array}$ & $\begin{array}{c}\text { Correlation between } \\
\text { Proportion of Large Firms } \\
\text { and Agg. Productivity }\end{array}$ \\
\hline Services (ISIC 50-74) & 0.69 & 0.62 \\
Manufacturing (ISIC 15-37) & 0.74 & 0.68 \\
Food products, beverage and tobacco (ISIC 15-16) & 0.44 & 0.39 \\
Textiles and textile products (ISIC 17-18) & 0.51 & 0.38 \\
Tanning and dressing of leather (ISIC 19) & 0.40 & 0.19 \\
Wood products (ISIC 20) & 0.49 & 0.34 \\
Paper products, printing and publishing (ISIC 21-22) & 0.54 & 0.56 \\
Energy, chemical and plastic products (ISIC 23-25) & 0.76 & 0.53 \\
Other non-metallic mineral products (ISIC 26) & 0.74 & 0.74 \\
Basic metals and metal products (ISIC 27-28) & 0.59 & 0.47 \\
Manuf. of machinery and equipment (ISIC 29) & 0.67 & 0.54 \\
Electrical and optical equipment (ISIC 30-33) & 0.38 & 0.52 \\
Transport equipment (ISIC 34-35) & 0.37 & 0.27 \\
Manufacturing nec, recycling (ISIC 36-37) & 0.31 & 0.61 \\
\hline
\end{tabular}

Notes: Aggregate productivity is GDP per hour worked in 2005 USD constant prices. Employment data is total employees (engaged). Large firms refers to firms with 250 or more employees. The correlation is calculated each year for each country in the sample for the reported industry, and then averaged for the 2004-2009 period and over all countries in the sample. The countries in the sample are Austria, Belgium, Denmark, Finland, Germany, Greece, Italy, Netherlands, Portugal, Spain, Sweden, and the United Kingdom. Data for industries within manufacturing are only available for the period 2004-2007. Industry codes are ISIC Rev.3.

Source: OECD Annual National Accounts and SDBS Structural Business Statistics. 
Table A-2: Alternative Decomposition: Changing Weights Only

\begin{tabular}{|c|c|c|c|c|c|}
\hline & \multirow[b]{3}{*}{$\begin{array}{l}\text { Weighted labor productivity } \\
\qquad(\text { Germany }=100)\end{array}$} & \multicolumn{4}{|c|}{ Counterfactuals } \\
\hline & & \multicolumn{2}{|c|}{ Germany's weights } & \multicolumn{2}{|c|}{ Greece's weights } \\
\hline & & $\begin{array}{l}\text { Weighted labor } \\
\text { productivity }\end{array}$ & $\begin{array}{l}\% \text { change in } \\
\text { productivity }\end{array}$ & $\begin{array}{l}\text { Weighted labor } \\
\text { productivity }\end{array}$ & $\begin{array}{l}\% \text { change in } \\
\text { productivity }\end{array}$ \\
\hline Belgium & 113 & 120 & $+6 \%$ & 99 & $-13 \%$ \\
\hline Finland & 109 & 109 & $0 \%$ & 100 & $-8 \%$ \\
\hline UK & 108 & 107 & $-1 \%$ & 100 & $-8 \%$ \\
\hline Austria & 107 & 110 & $+3 \%$ & 95 & $-11 \%$ \\
\hline Sweden & 101 & 102 & $+1 \%$ & 93 & $-9 \%$ \\
\hline Germany & 100 & 100 & - & 91 & $-9 \%$ \\
\hline Netherlands & 96 & 99 & $+3 \%$ & 84 & $-12 \%$ \\
\hline Denmark & 94 & 94 & $0 \%$ & 99 & $+6 \%$ \\
\hline Spain & 87 & 98 & $+13 \%$ & 79 & $-9 \%$ \\
\hline Italy & 82 & 100 & $+22 \%$ & 77 & $-7 \%$ \\
\hline Greece & 65 & 91 & $+40 \%$ & 65 & - \\
\hline Portugal & 55 & 69 & $+24 \%$ & 49 & $-11 \%$ \\
\hline
\end{tabular}

Notes: This table reports an alternative decomposition to the one reported in Table 2 . The counterfactuals maintain each country's own firm productivities $(\theta \mathrm{s}$ in equation 1 ) and replace each country's employments shares (the $\omega s$ ) for Germany's and Greece's employment shares, respectively. Data includes Total Industry, Market Services, and Construction (ISIC Rev.3 10-74). Data is calculated each year and then averaged for the 2004- 2009 period.

Source: SDBS Structural Business Statistics and author's calculations

\section{Appendix B. Aggregate Total Factor Productivity and Firm Pro- ductivity}

Individual $i$ is endowed with production function $y_{i}$, which takes inputs $k_{i}$ and $n_{i}$ combines them with a Cobb-Douglas technology

$$
y_{i}\left(k_{i}, n_{i}\right)=a_{i} k_{i}^{\alpha} n_{i}^{\gamma}
$$

where $\alpha+\gamma<1$. The first order conditions from the firm's problem are

$$
\begin{aligned}
\alpha \frac{y_{i}}{k_{i}} & =r, \\
\gamma \frac{y_{i}}{n_{i}} & =w .
\end{aligned}
$$

The ratio between marginal products is

$$
\frac{n_{i}}{k_{i}}=\frac{r \gamma}{w \alpha} .
$$


Obtain expressions for unconditional factor demand by substituting (B.4) back into the first order conditions (B.2) and (B.3),

$$
\begin{aligned}
& k_{i}(r, w)=B^{\frac{1}{1-\alpha-\gamma}} \frac{\alpha}{r} a_{i}^{\frac{1}{1-\alpha-\gamma}}, \\
& n_{i}(r, w)=B^{\frac{1}{1-\alpha-\gamma}} \frac{\gamma}{w} a_{i}^{\frac{1}{1-\alpha-\gamma}} .
\end{aligned}
$$

Where $B=\left(\left(\frac{\alpha}{r}\right)^{\alpha}\left(\frac{\gamma}{w}\right)^{\gamma}\right)$. Define $K=\sum_{i} k_{i} \pi_{i}, N=\sum_{i} n_{i} \pi_{i}$ and $Y=$ $\sum_{i} y_{i} \pi_{i}$, where $\pi_{i}$ is the fraction of projects of type $i$ that are operated.

Aggregate equations (B.5) and (B.6) and divide both sides by $\sum_{i} \pi_{i} a_{i}^{\frac{1}{1-\alpha-\gamma}}$ to obtain

$$
\begin{aligned}
& K \cdot\left(\sum_{i} \pi_{i} a_{i}^{\frac{1}{1-\alpha-\gamma}}\right)^{-1}=B^{\frac{1}{1-\alpha-\gamma}} \frac{\alpha}{r} \\
& N \cdot\left(\sum_{i} \pi_{i} a_{i}^{\frac{1}{1-\alpha-\gamma}}\right)^{-1}=B^{\frac{1}{1-\alpha-\gamma}} \frac{\gamma}{w} .
\end{aligned}
$$

Substitute back into (B.5) and (B.6),

$$
\begin{aligned}
& k_{i}(K)=K \frac{a_{i}^{\frac{1}{1-\alpha-\gamma}}}{\sum_{i} \pi_{i} a_{i}^{\frac{1}{1-\alpha-\gamma}}}, \\
& n_{i}(N)=N \frac{a_{i}^{\frac{1}{1-\alpha-\gamma}}}{\sum_{i} \pi_{i} a_{i}^{\frac{1}{1-\alpha-\gamma}}} .
\end{aligned}
$$

Plugging back into the individual production function (B.1) yields

$$
y_{i}=a_{i}^{\frac{1}{1-\alpha-\gamma}}\left(\sum_{i} \pi_{i} a_{i}^{\frac{1}{1-\alpha-\gamma}}\right)^{-\alpha-\gamma} K^{\alpha} N^{\gamma} .
$$

Aggregating one last time we find the expression for sector output,

$$
Y=A K^{\alpha} N^{\gamma}
$$


where

$$
A \equiv\left(\sum_{i} \pi_{i} a_{i}^{\frac{1}{1-\alpha-\gamma}}\right)^{1-\alpha-\gamma}
$$

\section{Appendix C. Ouput of False Report}

Substitute the marginal ratios (B.4) into the production function (B.1) and solve for conditional factor demand

$$
\begin{gathered}
y_{i}\left(w, r, k_{i}\right)=a_{i} B\left(\frac{r}{\alpha}\right)^{\alpha+\gamma} k_{i}^{\alpha+\gamma} \\
y_{i}\left(w, r, n_{i}\right)=a_{i} B\left(\frac{w}{\gamma}\right)^{\alpha+\gamma} n_{i}^{\alpha+\gamma}
\end{gathered}
$$

with $B$ as defined in Appendix B. Solving for factors, we get conditional factor demand,

$$
\begin{aligned}
k_{i}\left(w, r, y_{i}\right) & =\frac{\alpha}{r} B^{-\frac{1}{\alpha+\gamma}} a_{i}^{-\frac{1}{\alpha+\gamma}} y_{i}^{\frac{1}{\alpha+\gamma}} \\
n_{i}\left(w, r, y_{i}\right) & =\frac{\gamma}{w} B^{-\frac{1}{\alpha+\gamma}} a_{i}^{-\frac{1}{\alpha+\gamma}} y_{i}^{\frac{1}{\alpha+\gamma}}
\end{aligned}
$$

Substituting into the cost function, $\kappa_{i}\left(w, r, y_{i}\right)=r k_{i}\left(w, r, y_{i}\right)+w n_{i}\left(w, r, y_{i}\right)+$ $f$ and substituting in for $B$,

$$
\kappa_{i}\left(w, r, y_{i}\right)=(\alpha+\gamma)\left(\left(\frac{\alpha}{r}\right)^{\alpha}\left(\frac{\gamma}{w}\right)^{\gamma}\right)^{-\frac{1}{\alpha+\gamma}} a_{i}^{-\frac{1}{\alpha+\gamma}} y_{i}^{\frac{1}{\alpha+\gamma}}+f
$$

Find output by plugging the cost function into the firm problem and maximize to get

$$
y_{i}(w, r)=\left(\left(\frac{\alpha}{r}\right)^{\alpha}\left(\frac{\gamma}{w}\right)^{\gamma}\right)^{\frac{1}{1-\alpha-\gamma}} a_{i}^{\frac{1}{1-\alpha-\gamma}}
$$

We can rewrite the cost function as

$$
\kappa_{i}\left(w, r, y_{i}\right)=\psi_{i} y_{i}^{\frac{1}{\alpha+\gamma}}+f
$$

where $\psi_{i} \equiv a_{i}^{-\frac{1}{\alpha+\gamma}}(\alpha+\gamma)\left(\left(\frac{r}{\alpha}\right)^{\alpha}\left(\frac{w}{\gamma}\right)^{\gamma}\right)^{\frac{1}{\alpha+\gamma}}$. 
An entrepreneur who misrepresents his type is given funds $\psi_{-i} y_{-i}^{\frac{1}{\alpha+\gamma}}+f$ but his real production costs are $\psi_{i}\left(y_{i}^{F}\right)^{\frac{1}{\alpha+\gamma}}+f$. Making these two equal yields $y_{i}^{F}=\frac{a_{i}}{a_{-i}} y_{-i}$.

\section{Appendix D. Solution to the Contract}

The solution begins with the no-private-information problem, and then adds private information.

Rewrite the problem as a linear programming problem, with $\tilde{L}_{i} \equiv e_{i} L_{i}$

$$
\begin{array}{ccc}
\max _{e_{\ell}, e_{h}, \tilde{L_{\ell}}, \tilde{L_{h}}, \tilde{L_{\ell}^{F}}, \tilde{L_{h}^{F}}} \mathbb{E}[c]=\nu\left(e_{\ell}\left(y_{\ell}-w\right)-\tilde{L_{\ell}}\right)+(1-\nu)\left(e_{h}\left(y_{h}-w\right)-\tilde{L_{h}}\right)+(\mathrm{D} .1) \\
\text { s.t. } & e_{\ell}\left(y_{\ell}-w\right)-\tilde{L_{\ell}} \geq e_{h}\left(y_{\ell}^{F}-w\right)-\tilde{L_{\ell}^{F}} \\
e_{h}\left(y_{h}-w\right)-\tilde{L_{h}} \geq e_{\ell}\left(y_{h}^{F}-w\right)-\tilde{L_{h}^{F}} & \text { (D.2) } \\
\nu e_{\ell}\left(\kappa_{\ell}\right)+(1-\nu) e_{h}\left(\kappa_{h}\right) \leq \nu \tilde{L_{\ell}}+(1-\nu) \tilde{L_{h}}+\eta & \text { (D.4) } \\
0 \leq \tilde{L_{i}} \leq e_{i} \phi y_{i} \forall i & \text { (D.5) } \\
0 \leq \tilde{L_{i}^{F}} \leq e_{i} \phi y_{i}^{F} \quad \forall i & \text { (D.6) } \\
0 \leq e_{i} \leq 1 \quad \forall i & \text { (D.7) }
\end{array}
$$

No Private Information. In the no-private-information environment, (D.2) and (D.3) are absent. Notice the effect of $\tilde{L}_{\ell}$ and $\tilde{L}_{h}$ is neutral: Increasing either reduces (D.1) by the same amount it relaxes (D.4) so their values are indeterminate. The proportion of high ability projects funded is the maximum possible since it increases (D.1) by more than it reduces (D.4) because $y_{h}-\kappa_{h}-w>0$. The amount of funded projects $e_{h} \geq e_{\ell}$ because $y_{h}-\kappa_{h}-w>y_{\ell}-\kappa_{\ell}-w$. The proportion of low projects funded is $e_{\ell}=0$ if low type is unprofitable because it constraints (D.4) by more than it increases (D.1) $y_{\ell}-\kappa_{\ell}-w<0$, and positive otherwise.

Private information. If $w>\frac{a_{\ell}}{a_{h}} y_{h}(1-\phi)$ then the no-private-information allocations are incentive compatible.

Recall the incentive compatibility constraint for low type,

$$
e_{\ell}\left(y_{\ell}-L_{\ell}\right)+\left(1-e_{\ell}\right) w \geq e_{h}\left(y_{\ell}^{F}-L_{\ell}^{F}\right)+\left(1-e_{h}\right) w .
$$


If low ability agent is unprofitable $\left(y_{\ell}-\kappa_{\ell}<w\right)$ or there are sufficient highability agents $\left(e_{h}<1\right)$, then $e_{\ell}=0$ in the no-private-information allocation. This allocation is incentive compatible if

$$
w \geq e_{h}\left(y_{\ell}^{F}-L_{\ell}^{F}\right)+\left(1-e_{h}\right) w .
$$

A low-productivity entrepreneur who lies obtains output $y_{\ell}^{F}=\frac{a_{\ell}}{a_{h}} y_{h}$ (Appendix C). To deter lying, it is optimal to set the punishment for lying as high as possible, $L_{\ell}^{F}=\phi y_{\ell}^{F}=\phi \frac{a_{\ell}}{a_{h}} y_{h}$.

Substitute this expression in (D.9) to obtain,

$$
w \geq e_{h} \frac{a_{\ell}}{a_{h}} y_{h}(1-\phi)+\left(1-e_{h}\right) w .
$$

Substract $\left(1-e_{h}\right) w$ and divide by $e_{h}$ from both sides to obtain the threshold wage beyond which the no-private-information allocation is always incentive compatible.

$$
w \geq \frac{a_{\ell}}{a_{h}} y_{h}(1-\phi) .
$$

Incentive compatibility binds: $w<\frac{a_{\ell}}{a_{h}} y_{h}(1-\phi)$

First, setting $\tilde{L_{i}^{F}}=e_{i} \phi y_{i}^{F}$ for all $i$ is optimal since it relaxes (D.2) and (D.3) but has not other effects elsewhere.

Next, (D.2) binds and, rearranging, we obtain

$$
\frac{e_{h}}{e_{\ell}}=\frac{y_{\ell}-L_{\ell}-w}{(1-\phi) \frac{a_{\ell}}{a_{h}} y_{h}-w} .
$$

Feasibility always binds, so combining (D.12) with (D.4) one obtains

$$
e_{h}=\frac{\eta}{\nu\left(\kappa_{\ell}-L_{\ell}\right)\left(\frac{(1-\phi) \frac{a_{\ell}}{a_{h}} y_{h}-w}{y_{\ell}-L_{\ell}-w}\right)+(1-\nu)\left(\kappa_{h}-L_{h}\right)}
$$

and the amount of low-ability projects funded,

$$
e_{\ell}=\frac{\eta}{\nu\left(\kappa_{\ell}-L_{\ell}\right)+(1-\nu)\left(\kappa_{h}-L_{h}\right)\left(\frac{y_{\ell}-L_{\ell}-w}{(1-\phi) \frac{Q_{\ell}}{a_{h}} y_{h}-w}\right)} .
$$

The remaining arguments of the contract are $L_{h}$ and $L_{\ell}$. We already 
argued that the direct effect of $\tilde{L_{h}}$ in the objective function and feasibility constraint is neutral. Yet, increasing $L_{h}$ has another indirect effect on the objective function by increasing the quantity of projects $e_{h}$ and $e_{\ell}$. To see this, notice that $\frac{\partial e_{h}}{\partial L_{h}}>0$ and $\frac{\partial e_{\ell}}{\partial L_{h}}>0$ in expressions (D.13) and (D.14). Since $\frac{\partial c^{e}}{\partial e_{\ell}}>0$ and $\frac{\partial c^{e}}{\partial e_{h}}>0$ in (D.1), $L_{h}=\phi y_{h}$, unless (D.3) binds and then $L_{h}$ is pinned down by (D.3) with equality.

$\tilde{L}_{\ell}$ is also directly neutral on the objective function and the feasibility constraint. Its indirect effect on the objective function through $e_{\ell}$ is positive, as $\frac{\partial e_{\ell}}{\partial L_{\ell}}>0$. However, its indirect effect through $e_{h}$ depends on the profitability of low-productivity projects. If low-type projects are profitable

$\left(y_{\ell}-\kappa_{\ell}>w\right)$ then $\frac{\partial e_{h}}{\partial L_{\ell}}>0$ because $\frac{\partial}{\partial L_{\ell}} \frac{\kappa_{\ell}-L_{\ell}}{y_{\ell}-w-L_{\ell}}<0$ in the denominator of expression (D.13). Hence increasing $L_{\ell}$ has an overall positive effect on the objective function, and $L_{\ell}=\phi y_{\ell}$. However, if low types are unprofitable, then $\frac{\partial e_{h}}{\partial L_{\ell}}<0$ by the opposite argument. Since high-productivity projects are more beneficial to the objective function than low productivity projects $\left(\frac{\partial c^{e}}{\partial e_{\ell}}<\frac{\partial c^{e}}{\partial e_{h}}\right)$, then the negative effect of increasing $L_{\ell}$ dominates and $L_{\ell}$ is driven to its lowest value, $L_{\ell}=0$.

\section{Appendix E. Modified Model with Multiple Sectors}

Recall the production function for the representative firm in sector $j$,

$$
y_{j}=A_{j} k_{j}^{\alpha} n_{j}^{\gamma}
$$

Take first order conditions of sector's $j$ problem

$$
\begin{gathered}
p_{j} \alpha \frac{y_{j}}{k_{j}}=r \\
p_{j} \gamma \frac{y_{j}}{n_{j}}=w
\end{gathered}
$$

Substitute back in the production function to get

$$
p_{j}=y_{j}^{\frac{1-\alpha-\gamma}{\alpha+\gamma}} A_{j}^{\frac{-1}{\alpha+\gamma}}\left(\left(\frac{r}{\alpha}\right)^{\alpha}\left(\frac{w}{\gamma}\right)^{\gamma}\right)^{\frac{1}{\alpha+\gamma}}
$$


Aggregate the first order conditions to get

$$
\begin{aligned}
& r K=\alpha \sum_{j} p_{j} y_{j} \\
& w N=\gamma \sum_{j} p_{j} y_{j}
\end{aligned}
$$

By the assumption of zero profits for the final good producer, $Y=$ $\sum_{j} p_{j} y_{j}$. Substitute in (E.2) and (E.3),

$$
\begin{aligned}
& r K=\alpha Y \\
& w N=\gamma Y
\end{aligned}
$$

These expressions allow us to solve for prices and parameters in equation (E.1),

$$
\left(\left(\frac{r}{\alpha}\right)^{\alpha}\left(\frac{w}{\gamma}\right)^{\gamma}\right)^{\frac{1}{\alpha+\gamma}}=Y\left(K^{\alpha} N^{\gamma}\right)^{-\frac{1}{\alpha+\gamma}}
$$

Now take first order conditions from the final good producer problem (19) and aggregate to get

$$
\left(\sum_{j} p_{j}^{-\frac{\theta}{1-\theta}}\right)^{-\frac{1-\theta}{\theta}}=1
$$

Combining (E.1), (E.6) and (E.7) we get expression (20).

\section{Appendix F. Alternative setup}

In the model, the imperfect enforcement parameter affects repayments for both truthful and false reports. Suppose instead that the repayment limit from truthful and false reports are governed by different parameters, $\phi^{T}$ and $\phi^{F}$. Bankruptcy efficiency can now be mapped to $\phi^{F}$ without affecting $\phi^{T}$. This specification has the advantage that the average quality of firms and the quantity of firms produce sharper results: the average quality of firms decreases with the recovery rate even when low productivity projects are profitable. The disadvantage of this specification lies in the credibility of the quantitative experiment, as $\phi^{T}$ is now a free parameter. Suppose that $\phi^{T}=\phi^{F}=0.8$ for the US. Keeping $\phi^{T}$ at 80 percent and varying only 
$\phi^{F}$ as in the recovery rate data still produces significant drops in TFP and labor productivity, though smaller than in the main experiment. When the recovery rate goes from 80 to 45 cents on the dollar, TFP now drops by 17.6 percent (as opposed to 30.7 percent), and labor productivity drops by 30.6 percent (as opposed to 47.8 percent). 
Amaral, P. And E. Quintin, "Limited Enforcement, Financial Intermediation, and Economic Development," International Economic Review 51 (August 2010), 785-811. 8, 22

Araujo, A. P., R. V. Ferreira and B. Funchal, "The Brazilian bankruptcy law experience," Journal of Corporate Finance 18 (2012), 9941004. 5

AtKeson, A. And P. J. Kehoe, "Modeling and Measuring Organization Capital," Journal of Political Economy 113 (October 2005), 1026-1053. 22,24

Banerjee, A. V. And B. Moll, "Why Does Misallocation Persist?," American Economic Journal: Macroeconomics 2 (2010), 189-206. 9

Barseghyan, L. and R. DiCecio, "Entry costs, industry structure, and cross-country income and TFP differences," Journal of Economic Theory 146 (2011), 1828-1851. 7

Bartelsman, E., J. Haltiwanger and S. Scarpetta, "Cross-Country Differences in Productivity: The Role of Allocation and Selection," American Economic Review 103 (2013), 305-34. 9, 1.1, 14

BAsu, S., "Procyclical Productivity: Increasing Returns or Cyclical Utilization?," The Quarterly Journal of Economics 111 (1996), 719-751. 24

BAsu, S. And J. G. Fernald, "Are apparent productive spillovers a figment of specification error?," Journal of Monetary Economics 36 (1995), $165-188.22,24$

Basu, S. And M. S. Kimball, "Cyclical Productivity with Unobserved Input Variation," NBER Working Papers 5915, National Bureau of Economic Research, Inc, February 1997. 24

Becker, B. And J. Josephson, "Insolvency Resolution and the Missing High-Yield Bond Markets," Review of Financial Studies (2016). 30

Bento, P. and D. Restuccia, "Misallocation, Establishment Size, and Productivity," American Economic Journal: Macroeconomics (forthcoming). 1.1 
Bond, E. W., M. J. Crucini, T. Potter and J. Rodrigue, "Misallocation and productivity effects of the Smoot-Hawley tariff," Review of Economic Dynamics 16 (2013), 120 - 134, special issue: Misallocation and Productivity. 7

Buera, F. J., J. P. Kaboski And Y. Shin, "Finance and Development: A Tale of Two Sectors," American Economic Review 101 (August 2011), 1964-2002. 8

Cabral, L. M. B. And J. Mata, "On the Evolution of the Firm Size Distribution: Facts and Theory," American Economic Review 93 (2003), 1075-1090. 4

Caselli, F. And N. Gennaioli, "Dynastic Management," Economic Inquiry 51 (2013), 971-996. 8

Castany, L., E. Lpez-Bazo and R. Moreno, "Differences In Total Factor Productivity Across Firm Size - A Distributional Analysis," Ersa conference papers, European Regional Science Association, August 2005. 15

Caunedo, J., "Industry Dynamics, Investment and Uncertainty," mimeo, 2015. 9

Cole, H. L., J. Greenwood and J. M. SAnchez, "Why Doesn't Technology Flow From Rich to Poor Countries?," Econometrica 84 (2016), 1477-1521. 8

Corbae, D. And P. D'Erasmo, "Reorganization or Liquidation: Bankruptcy Choice and Firm Dynamics," mimeo, 2014. 1.1

Davydenko, S. A. And J. R. Franks, "Do Bankruptcy Codes Matter? A Study of Defaults in France, Germany, and the U.K.," The Journal of Finance 63 (2008), 565-608. 1

Djankov, S., O. Hart, C. McLiesh and A. Shleifer, "Debt Enforcement around the World," Journal of Political Economy 116 (December 2008), 1105-1149. 2.3

Erosa, A. And A. Hidalgo-Cabrillana, "On Finance As A Theory Of Tfp, Cross-Industry Productivity Differences, And Economic Rents," International Economic Review 49 (05 2008), 437-473. 1, 1.1, 20 
Eslava, M., J. Haltiwanger, A. Kugler And M. Kugler, "Trade and market selection: Evidence from manufacturing plants in Colombia," Review of Economic Dynamics 16 (2013), 135 - 158, special issue: Misallocation and Productivity. 7

Evans, D. S. And B. Jovanovic, "An Estimated Model of Entrepreneurial Choice under Liquidity Constraints," Journal of Political Economy 97 (August 1989), 808-27. 4

Foster, L., J. Haltiwanger and C. Syverson, "Reallocation, Firm Turnover, and Efficiency: Selection on Productivity or Profitability?," American Economic Review 98 (2008), 394-425. 11, 15

Gamboa-Cavazos, M. And F. Schneider, "Bankruptcy as a Legal Process," mimeo, Harvard University, 2007. 5

Gilchrist, S., J. W. Sim And E. Zakrajsek, "Misallocation and Financial Market Frictions: Some Direct Evidence from the Dispersion in Borrowing Costs," Review of Economic Dynamics 16 (January 2013), 159-176. 9

Gollin, D., "Getting Income Shares Right," Journal of Political Economy 110 (April 2002), 458-474. 23

Gomme, P. And P. Rupert, "Theory, measurement and calibration of macroeconomic models," Journal of Monetary Economics 54 (March 2007), 460-497. 5.1

Greenwood, J., J. M. Sanchez And C. WAng, "Quantifying the impact of financial development on economic development," Review of Economic Dynamics 16 (2013), 194 - 215, special issue: Misallocation and Productivity. 8

Guner, N., G. Ventura And X. Yi, "Macroeconomic Implications of Size-Dependent Policies," Review of Economic Dynamics 11 (October 2008), 721-744. 7

Hopenhayn, H. And R. Rogerson, "Job Turnover and Policy Evaluation: A General Equilibrium Analysis," Journal of Political Economy 101 (October 1993), 915-38. 7 
Hopenhayn, H. A., "On the Measure of Distortions," NBER Working Papers 20404, National Bureau of Economic Research, Inc, August 2014. 1

Hsien, C.-T. AND P. J. KLenow, "Misallocation and Manufacturing TFP in China and India," The Quarterly Journal of Economics 124 (November 2009), 1403-1448. 1.1

-, "Development Accounting," American Economic Journal: Macroeconomics 2 (January 2010), 207-23. 2

—_ "The Life Cycle of Plants in India and Mexico," The Quarterly Journal of Economics (2014). 1.1

Hsien, C.-T. And B. A. Olken, "The Missing "Missing Middle"," Journal of Economic Perspectives 28 (2014), 89-108. 15

Kalemli-Ozcan, S., B. Sorensen, C. Villegas-Sanchez, V. Volosovych and S. Yesiltas, "How to Construct Nationally Representative Firm Level data from the ORBIS Global Database," Working Paper 21558, National Bureau of Economic Research, September 2015. 10

Lagos, R., "A Model of TFP," The Review of Economic Studies 73 (2006), pp. $983-1007.7$

Lambert-Mogiliansky, A., K. Sonin and E. Zhuravskaya, "Are Russian Commercial Courts Biased? Evidence from a Bankruptcy Law Transplant," Journal of Comparative Economics (2007). 5

Leung, D., C. Meh and Y. Terajima, "Firm Size and Productivity," Working Papers 08-45, Bank of Canada, 2008. 15

LI, H., "Leverage and Productivity," mimeo, 2015. 9

Luchs, J., Robert E., "On the Size Distribution of Business Firms," The Bell Journal of Economics 9 (1978), pp. 508-523. 1

Midrigan, V. And D. Y. XU, "Finance and Misallocation: Evidence from Plant-Level Data," American Economic Review 104 (2014), 422-58. 9 
Moll, B., "Productivity Losses from Financial Frictions: Can SelfFinancing Undo Capital Misallocation?," American Economic Review 104 (2014), 3186-3221. 8

Moscoso-Boedo, H. J. And T. Mukoyama, "Evaluating the effects of entry regulations and firing costs on international income differences," Journal of Economic Growth 17 (2012), 143-170. 7

OECD, Financing SMEs and Entrepreneurs 2012: An OECD Scoreboard (OECD Publishing, 2012). 29

Olley, G. S. And A. PaKes, "The Dynamics of Productivity in the Telecommunications Equipment Industry," Econometrica 64 (1996), pp. 1263-1297. 2.2

Ponticelli, J. And L. S. Alencar, "Court Enforcement, Bank Loans, and Firm Investment: Evidence from a Bankruptcy Reform in Brazil *," The Quarterly Journal of Economics 131 (2016), 1365. 1, 1.1

Poschke, M., "The Firm Size Distribution across Countries and SkillBiased Change in Entrepreneurial Technology," IZA Discussion Papers 7991, Institute for the Study of Labor (IZA), February 2015. 1.1

Prescott, E. C. and R. M. Townsend, "Pareto Optima and Competitive Equilibria with Adverse Selection and Moral Hazard," Econometrica 52 (January 1984), 21-45. 3

Rajan, R. G. And L. Zingales, "Financial Dependence and Growth," American Economic Review 88 (June 1998), 559-86. 3, 5.1

Restuccia, D. and R. Rogerson, "Policy Distortions and Aggregate Productivity with Heterogeneous Plants," Review of Economic Dynamics 11 (October 2008), 707-720. 1.1

Rodano, G., N. Serrano-Velarde and E. Tarantino, "Bankruptcy Law and Bank Financing," Technical Report, IGIER Workin Paper Series, 2015. 5

Rodriguez-Delgado, J. D., "Bankruptcy and Firm Dynamics; The Case of the Missing Firms," IMF Working Papers 10/41, International Monetary Fund, February 2010. 1.1 
Rogerson, W. P., "The First-Order Approach to Principal-Agent Problems," Econometrica 53 (1985), 1357-67. 21

Senkal, A., "Misallocation and Recovery Rates," University of Virginia, mimeo, 2014. 1.1

Steinberg, J., "Information, Contract Enforcement, and Misallocation," University of Minnesota, mimeo, 2013. 8

Tamayo, C., "Bankruptcy Choice with Endogenous Financial Constraints," mimeo, 2015. 1.1 